\title{
A Framework for Ecological Decision Support Systems: Building the Right Systems and Building the Systems Right
}

Information and Technology Report

USGS/BRD/ITR-2001-0002

enlangered

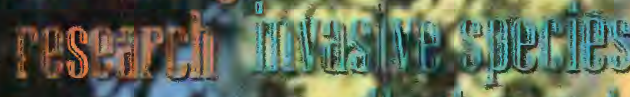





\section{A Framework for Ecological Decision Support Systems: Building the Right Systems and Building the Systems Right}

By Frank D’Erchia, Carl Korschgen, Maury Nyquist, Ralph Root, Rick Sojda, and Peter Stine

Information and Technology Report

USGS/BRD/ITR—2001-0002 


\section{U.S. Department of the Interior \\ Gale A. Norton, Secretary}

\section{U.S. Geological Survey \\ Charles G. Groat, Director}

U.S. Geological Survey, Reston, Virginia: 2001

Any use of trade, product, or firm names in this publication is for descriptive purposes only and does not imply endorsement by the U.S. Government.

Copies of this publication are available from the National Technical Information Service, 5285 Port Royal Road, Springfield, Virginia 22161 (1-800-5536847 or 703-487-4650). Copies also are available to registered users from the Defense Technical Information Center, Attn.: Help Desk, 8725 Kingman Road, Suite 0944, Fort Belvoir, Virginia 22060-6218 (1-800-2253842 or $703-767-9050$ ).

Suggested citation:

D’Erchia, F., Korschgen, C., Nyquist, M., Root, R., Sojda, R., and Stine, P., 2001, A framework for ecological decision support systems: building the right systems and building the systems right: U.S. Geological Survey, Biological Resources Division, Information and Technology Report USGS/BRD/ ITR-2001-0002, 50 p. 


\section{Contents}

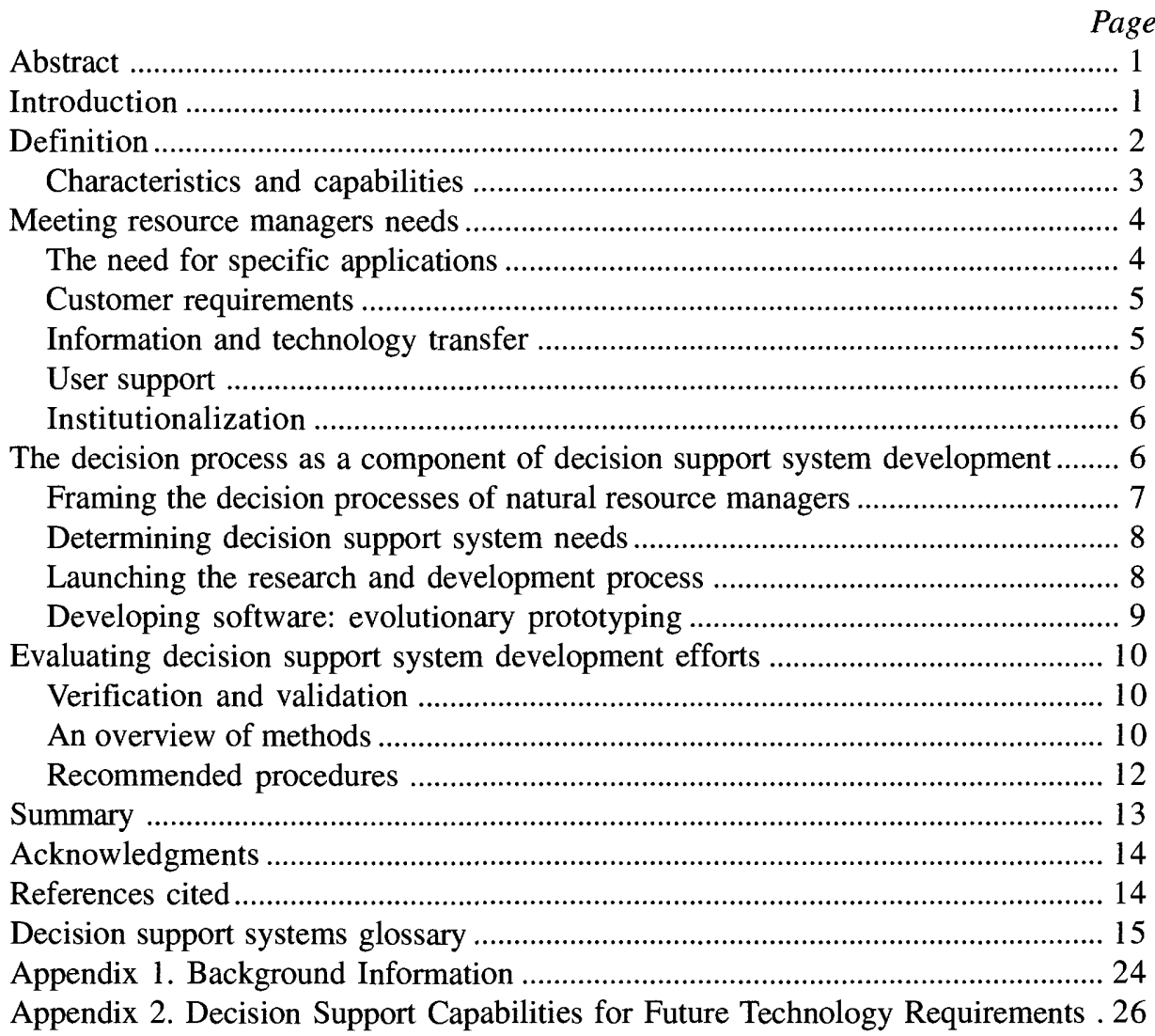

\section{Tables and Figures}

Table 1. Various approaches to decision support systems development and application 9

Figure 1. A recommended process for decision support systems development 



\section{A Framework for Ecological Decision Support Systems: Building the Right Systems and Building the Systems Right}

By

Frank D'Erchia

U.S. Geological Survey

Biological Resources Division

Central Region

P.O. Box 25046

Denver, C0 80225-0046

Carl Korschgen

U.S. Geological Survey

Columbia Environmental Research Center

4200 New Haven Road

Columbia, M0 65201

Maury Nyquist

U.S. Geological Survey

Center for Biological Informatics

P.0. Box 25046

Denver, CO 80225-0046

\author{
Ralph Root \\ U.S. Geological Survey \\ Rocky Mountain Mapping Center \\ P.O. Box 25046 \\ Denver, CO 80225-0046 \\ Rick Sojda \\ U.S. Geological Survey \\ Northern Rocky Mountain Science Center \\ P.O. Box 173492 \\ Montana State University \\ Bozeman, MT 59717-3492 \\ Peter Stine \\ U.S. Forest Service \\ Pacific Southwest Research Station \\ Sierra Nevada Research Center \\ 801 I St. \\ Sacramento, CA 95814
}

\section{Abstract}

Workshops in the late 1990's launched the commitment of the U.S. Geological Survey's Biological Resources Division (BRD) to develop and implement decision support systems (DSS) applications. One of the primary goals of this framework document is to provide sufficient background and information for Department of the Interior (DOI) bureau stakeholders and other clients to determine the potential for DSS development. Such an understanding can assist them in carrying out effective land planning and management practices. This document provides a definition of DSS and its characteristics and capabilities. It proceeds to describe issues related to meeting resource managers needs, such as the needs for specific applications, customer requirements, information and technology transfer, user support, and institutionalization. Using the decision process as a means to guide DSS development and determine users needs is also discussed. We conclude with information on methods to evaluate DSS development efforts and recommended procedures for verification and validation.

Key words: Adaptive management, Biological Resources Division, decision making process, decision support systems, DSS, resource managers, USGS.

\section{Introduction}

Since the time that people began living in ordered societies, some form of organized decision making has been an integral part of everyday existence. Before information processing technologies were developed, decisions were made entirely by human deliberation, aided by verbal and perhaps some printed and other visual information. In today's environment of highly 
developed information technologies, many powerful tools exist to improve and refine decision making, although it remains a human-directed process.

In the 1990's, significant advances in computing power, operating systems, memory and storage capacity, and applications software made it feasible to use large databases and geospatial information in decision support system (DSS) applications. Combining data, information, and computer-based and noncomputerbased tools and services within a structured DSS framework can improve both the process and outcomes of decision making. In the current world of connectivity, a DSS can process data online and be "seamlessly" accessed by many different hardware and software systems.

Use of a DSS helps resource managers better define problems, systematically review the decisions they make, analyze the factors that influence those decisions, identify information that is available with respect to these factors, and predict the effects of making decisions with and without desired information. A DSS can also provide a framework for adaptive management, information feedback loops, and continuous improvement of the decision making process.

To coordinate ecological DSS efforts, the U.S. Geological Survey's (USGS) Office of Biological Informatics and Outreach sponsored a Biological Resources Division (BRD) Decision Support Systems Workshop in October 1998 (Getter and others, 1999). In preparation for the workshop, a questionnaire was distributed to all USGS staff; the results were used to construct a database of USGS resources related to decision support systems. A Web page (http:// biology.usgs.gov/dss/meeting.html) documents the workshop proceedings and the results of the USGSwide survey. The abstracts included in the proceedings can give insight into how decision support systems are currently being used.

Workshops in the late 1990's launched the commitment of the USGS BRD to develop and implement DSS applications (see Appendix 1 for more complete background information). The BRD assists Department of the Interior (DOI) land management units and resource managers with a wide array of biological research activities, including data analysis, modeling, and decision support required for effective land-use planning and management of parks, refuges, other resource areas and their environs (USGS Biological Resources Division, 1996). One of the primary goals of this framework document is to provide sufficient background and information for DOI bureau stakeholders and other clients to determine the potential for DSS development that can assist them in carrying out effective land planning and management practices. The
BRD will continue to play a significant role in DSS research, offering the biological community unique capabilities for problem identification, data collection methodologies, analysis and modeling, evaluation of solution sets, and selection of optimal solutions.

\section{Definition}

A DSS can be defined generally as an interactive, computer-based tool or collection of tools that use(s) information and models to improve the process and outcome of decision making. Many definitions of DSS exist (Bonczek and others, 1981; Andriole, 1989; Carter and others, 1992; Holsapple and Whinston, 1996). Most identify the need for a combination of database, interface, and model components directed at a specific but poorly structured problem. Decision support systems can be simple or complex. A simple decision support tool might allow the user to view and query the data, such as in a database. A more sophisticated DSS incorporates problem structuring, geospatial data, models, analytical tools, and user query screens. Such a system would address statistical properties of results and provide reports, output maps, and graphs. Geographic information systems (GIS) provide information in a spatial context that can help managers make decisions. But in terms of these definitions, a standalone GIS would be regarded as a decision support tool, not a complete decision support system, because it lacks both support for the use of problem specific models and the ability to assist in problem definition.

Before categorizing an analysis method as a DSS or a decision support tool, we must first determine whether the user is being provided value-added assistance that transcends the original intent of the analytical method. Databases, or some forms of information or knowledge, are the building blocks for a DSS. Developers of DSS can add valuable, specific biological knowledge to these databases as well as provide technological expertise for applying the data and for constructing models. Making this distinction-that a DSS has these value-added qualities-helps prospective users clarify whether they require a customized DSS to address their problem or whether a stand-alone tool will be sufficient.

Some DOI bureau needs can be supported simply by providing accurate data in a usable format; for example, providing landcover data for the area of interest with a simple GIS tool to view and overlay the data. Land managers can examine changes over time and compare this information with other relevant data to help them make informed decisions. But if a more complicated 
question is being asked, a DSS is useful. Decision Support Systems can be designed to query the user, and through models and analytical tools, integrate that user input with available data. The DSS returns various scenarios based upon the value of parameters entered by the user. By being able to view and compare the projected results of the various simulations, the user can make a more informed decision.

\section{Characteristics and capabilities}

In addition to the biological sciences, decision support systems that integrate GIS and simulation models can be widely applied in the engineering, planning, and legislative domains (Brimicombe, 1992). A wide variety of databases, models, display and visualization methods, and other tools are currently available, and still more are under development.

Decision support systems share several major characteristics:

- They include data, images/graphics, simulation models, information, or knowledge.

- They are designed to assist managers in the decision process for semistructured (or unstructured) tasks and problems.

- They support, rather than replace, managerial judgment.

- Their objective is usually to improve the effectiveness and thoroughness of the decisions and sometimes the efficiency with which the decisions are being made.

Typically, decision support systems:

- Use readily accessible and affordable hardware and software.

- Provide intuitive user interfaces that are adaptable to various levels of sophistication.

- Provide modularity to allow incremental development and building-block interaction with other systems.

- Allow for Internet connectivity and the ability to access and interact with remote databases, tools, models, and systems.

- Incorporate interoperability to allow use of numerous components and sources of data tools, models, and systems.

- Presume a need for cooperative development with users.

The following components and capabilities may be part of a DSS:

- GIS technology.

- Ability to accept and use real-time data.

- Ability to access and use textual materials.
- Ability to select different spatial and temporal scales.

- Modeling and simulation tools.

- Mechanisms to allow structured problem definition and stakeholder involvement.

- Visualization tools to display data, relationships, and projected results.

- Tools to facilitate adaptive management and monitoring.

- Means to depict uncertainty in data, relationships, or results.

- Methods to treat multiple goals, objectives, and measures.

- Ability to create and store scenarios.

- Ability to assemble components and integrate data as needed.

- Ability to document lineage of output.

A DSS can be developed as a network system-one that is linked to large data warehouses to serve multiple users - or as an independent system. These two types of DSS are adaptable to a broad range of uses. In both instances, decision makers have access to local and external data. Network decision support systems can range from fairly simple systems to complex, dataintensive, and analytically sophisticated information systems that provide access to a series of databases, models, and expert systems. Most DSS development in the BRD to date has focused on the independent DSS, primarily because consistent, expansive, seamless, and interoperable databases and framework systems are rare. However, framework systems with interoperable databases are under development in the public and private sectors.

Not only is access to data important, but the quantity and quality of available data and the degree to which data are georeferenced are important aspects of a DSS. Given the increasing popularity of GIS, more geospatial data are becoming available and usable in a DSS; however, while data are abundant for some natural resource issues, other issues appropriate for DSS application have minimal data available. Insight into the quality of data, partly through well-documented metadata, will help in evaluating the data's usefulness. Without metadata, data accuracy and reliability are unknown. Indeed, the use of spatial data may be inappropriate when addressing a specific problem; instead, other reliable information and knowledge may be required.

It is easy to develop unrealistic expectations when building a DSS. Although the capabilities of a DSS range from limited to highly sophisticated, even the most complex DSS will not be designed to replace decision makers, nor will it eliminate poor decisions or make good decisions without the input of experienced, 
knowledgeable people. Managers must continue to ask the correct questions and draw the correct conclusions from the information they receive. If lack of knowledge and expertise can potentially result in a poor decision, a DSS can greatly assist the user by offering those missing pieces (Klein, 1998).

\section{Meeting resource managers needs}

The overriding consideration in developing an effective DSS is to involve both the decision makers and the research and development scientists in the entire process. One aspect of this involvement is to think like an application builder rather than a programmer because "application builders are more interested in improving decision making than in automating it" (Carter and others, 1992). Alter (1978) and Finlay (1994) identify six keys to success:

1. Devote the necessary time to clearly understand the needs of users.

2. When possible, tailor the system to individual user capabilities and management style.

3. Maintain close contact with the user throughout development.

4. Provide users with service rather than a product.

5. Design a simple system that does not overload the user.

6. Train users according to individual levels of expertise and rates of learning.

In addition, we recommend development of a specific team (after Sprague and Carlson, 1982; Carter and others, 1992) that should include upper-level management, actual users, and system developers. Such a team's purpose is to guide the project from inception through implementation, maintenance, and reengineering, focusing especially on communication issues.

\section{The need for specific applications}

Our national wildlife refuges, national parks, and other conservation areas are under increasing development and recreational pressures, resulting in a need for innovative management strategies. The DOI will need enhanced abilities to provide state-of-the-art management, protection, and interpretation of its resources. To meet these needs, information of the highest quality must be collected and applied, and an interdisciplinary, coordinated approach that considers both socioeconomic and environmental data and concerns must be used in the decision-making process.
A common vocabulary is necessary to ensure clear communication in discussions of DSS development with DOI resource managers and other partners. For example, some managers may interchangeably use the terms "expert system," "database," "GIS," "information system," and "DSS." Clearly defining at the planning stages exactly what a DSS is - and isn't-will ensure that the user's needs and expectations are addressed appropriately. A DSS should provide a more powerful context for decision making (through DSS and decision-maker interaction) rather than be an end in and of itself (Power and Kaparthi, 1998).

The use of decision support systems can enable natural resource management bureaus to make decisions that support long-term management goals and priorities. Decision analysis and support systems provide structures for systematically analyzing the factors involved in decisions and determining the quantity and quality of information related to those factors. A well designed DSS also provides decision makers with frameworks that assess the relative risks of making decisions in the absence of complete information. In some contexts, the structure ensures that the decision-making process is institutionalized and archived.

The DOI bureaus would benefit by having decision support systems for the lands and resources that they manage. For example, refuge managers and national park superintendents often need to compile and analyze information on natural and cultural resources within their refuge or park and develop "what if" scenarios for management alternatives. Bureau of Reclamation managers are incorporating a DSS in reservoir management. The Bureau of Land Management might be interested in a DSS related to oil development and sage grouse (Centrocercus urophasianus) habitat. Decision support tools can serve as electronic ecosystem encyclopedias that can be used to integrate and visualize a variety of data such as vegetation cover, land-use practices, roads, stream maps, species richness maps for plants and animals, census information, and output from research models. Products can be projected or printed in formats that effectively display historical and present conditions and visualize future management goals for planners and the public.

Because resource managers need to address a fairly broad array of questions, they likely want a desktop DSS that may contain a variety of geographic, scientific, sociological, and economic themes; models; metadata; text; and images. The most functional systems contain procedures for mapping, quantifying, graphically displaying, and modeling that can be understood by the user and the public. Because of varying capabilities and needs, creation of common platforms and interoperability should be looked at as 
goals, not absolute requirements in the development of decision support systems for DOI bureau land managers.

To ensure a client driven enterprise, flexibility is of paramount importance. Some clients need DSS development assistance that begins at the most basic starting point. Others will have varying degrees of DSS component development already under way. BRD involvement will depend upon each client's unique needs. Nevertheless, DOI clients can be grouped into two general levels of DSS sophistication: those who have a DSS need but do not have any existing DSS structure in their organization or existing tools, and those who have some kind of operational decision structure but lack integrated decision support tools. A primary goal of USGS support to DOI agencies should be to deliver products that reflect state-of-the-art biological knowledge in a mode the client can use most effectively.

A DSS based on spatial data could provide a structure for both management and science information (inventory, monitoring, and research) and activities or themes for the decision process. Once the problem has been identified, an initial step may be to compile the required geographic themes (e.g., digital topographic data, digital orthophoto quads or quarter quads, coverages of transportation, hydrography, vegetation, geology, soils, land cover and land use, rectified digital imagery of various types, boundaries, management units, points or areas of special interest, hazards, etc.) for DOI lands. Another early step might be to develop and incorporate the tools and models required for the analyses.

The BRD inventory contains many systems based on spatial data (Getter and others, 1999). Some are essentially advanced expert systems with customized computer programming to provide an interface for resource managers. The most common approach at the present time is to give users the ability to download software over the Internet and install it on their local personal computers. However, full functionality of applications is often not available over the Internet because of cost and programming limitations, processing power on the server, and speed of transmission. A notable exception is VegSpec, an Internet-based expert system (ironwood.itc.nrcs.usda.gov/scripts/ndisapi.dll/ vegspec21/pagVegspecStart) developed cooperatively by the USGS, U.S. Army Corps of Engineers, and the U.S. Department of Agriculture Natural Resources Conservation Service. This application assists the land manger in finding and selecting adapted plants for use in addressing vegetation restoration problems. Although largely a knowledge-based system, VegSpec does have data-based components, as it accounts for soil types and topographic variables (elevation, slope, and aspect).

\section{Customer requirements}

Ultimately, the tools and capabilities developed by the USGS must be of practical use to DOI managers and other partners. However complex or simple a DSS may be, it must address the needs of land and resource managers.

Decisions made by natural resource managers are inherently complex. Thousands of natural features and processes-attributes of a natural system that vary across time and space-might influence any given decision. Yet decisions must be made every day, and these decisions must be defensible. A natural resource manager requires a clear understanding of the current and future ecological ramifications of all decisions.

If a DSS is to be a trusted source of information, some basic issues must first be addressed before development and implementation. Although technological change throughout society has been monumental in recent years, natural resource managers in DOI have not necessarily been leaders in using advanced technologies (Biddle and others, 1995). Here we provide considerations to determine whether the time and resources required will meet DOI needs in a cost-effective manner.

\section{Information and technology transfer}

Effective and maximal use of decision support tools involves sharing information about the existing tools. Managers must be made aware of the existence of such tools, including their strengths and/or limitations and how they can best be used to solve problems.

Managers must be informed of what to expect from a specific DSS. Publication of individual applications on the Web and elsewhere will provide a method of continual communication to help maximize the usefulness of decision support systems. Open communication should occur at all levels-across agencies at the manager/scientist/technologist level, as well as up and down the chain of command-so that all participants in the decision-making process are kept adequately informed of what information is available and how it can be used.

Many decision support systems incorporate the most current and sophisticated technologies available. While use of these technologies enhances the capabilities of these systems, more specialized hardware and knowledge may be required to use such a DSS. Before developing a DSS, we must be sure that the intended users are ready for the specific technology by assessing the hardware and software capabilities of the intended users and by determining the type of scientific expertise the DSS requires. Providing a tool that has the desired capabilities but is not usable by the manager is, at best, 
a wasted effort. At worst, it can discourage managers from attempting to use these kinds of tools even when they eventually acquire the needed capabilities. The DSS user should not be dependent upon the system developer to successfully use the system.

Despite the efforts outlined above, there will likely still be resistance on the part of some potential users who are hesitant to take full advantage of available decision support tools and systems. The user without technical expertise may be reluctant to use a tool not yet fully understood. Managers and other decision makers will have to be convinced that the tool does an adequate job accounting for the meaningful assumptions and addressing the prominent features of a problem.

Furthermore, a basic tenet of decision support systems is that their focus is on support, i.e., managers are still responsible for making the actual decisions. Such software systems are not intended to supplant managers, but rather to assist them.

\section{User support}

Once the user adopts a DSS for a specific application, it is crucial that the BRD continue to provide user support and play a role in the DSS implementation stage. The majority of decision support systems will require some degree of training and technical support to bring users to a level where they are able to operate them effectively and take full advantage of all their features. Time allocated to provide training and technical assistance can be a sizeable commitment, but we must be prepared to fulfill this needed role. Once the managers and their staff have become comfortable using the tool, training and technical assistance will subside. There may be a demand for "on call" duty to help with particular problems, but the need for assistance should be minimal past the initial stages of training and technical assistance.

\section{Institutionalization}

The previous two sections point out some of the issues that will need to be addressed by both the client (e.g., DOI land management agencies) and DSS developer organizations (e.g., BRD or USGS). For DSS development and use to successfully advance at reasonable and sustainable rates, organizations must commit to institutionalizing this activity. The current situation with DSS is very similar to that of GIS in the early to mid 1980's. There were "pockets of GIS activity" in many organizations but little institutional support to foster its development and use or "glue" to make the disparate GIS activities into a coordinated, supported, valued, and viable organizational enterprise. Once GIS was institutionalized within the various organizations, it flourished. Other factors (e.g., less costly and more powerful hardware and software) also contributed to the successful adoption and use of GIS during that rapidly evolving period for GIS, but institutionalization was the catalyst needed to make GIS "standard operating procedure" within public and private organizations. The same situation pertains to DSS.

A full elaboration on what is needed to institutionalize DSS within BRD or USGS and client organizations will vary among organizations and is not appropriate here. However, some of the more generally applicable institutionalization issues that will need to be addressed are budget, staff, organizational buy-in and oversight, information and technology transfer, user support, and coordination. As such, BRD has started the institutionalization process, but there is still much more that needs to be done.

\section{The decision process as a component of decision support system development}

The process of decision making is generally recognized to include four stages (Carter and others, 1992). First is intelligence gathering. This gathering includes an analysis of the decisions to be made, how they will be made, and what information pertinent to those decisions is needed and where it might be available. An important component of this first stage is getting information into a format that is usable, accessible, and archived. Second is designing alternatives. This includes generating possibilities along with analyzing their potential outcomes. Often, the uncertainty associated with underlying information and the propagation of risks associated with decisions will be analyzed in this stage. Third is choosing among alternatives and is the process of actually making a decision. Fourth is the on-theground implementation of the decision along with an evaluation of that decision in terms of achieving goals. Simon's (1960) early seminal work on decision making did not explicitly recognize evaluation as a stage and combined on-the-ground implementation with stage three.

Recent work by Cleaves (1999) in the realm of collaborative decision making has produced two additional steps that precede Carter's first step of intelligence gathering. These steps are process mapping (i.e., deciding how the decision is to be made and who 
will make it) and problem framing (i.e., describing the problem to be solved or opportunity to be captured in terms of yardsticks for success, reference points from which to mark improvements, and boundaries that describe how much of the situation is "fair game" for a generation of alternatives). Process mapping and problem framing are extremely important first steps when working in a collaborative decision-making environment for place-based issues that require multiagency management programs, like the Mojave Desert Ecosystem Program or that require multiscale (e.g., local, county, state, and regional) planning activities, like the South Florida Ecosystem Program or the Pacific Northwest ecosystem.

Although DSS development must address all relevant stages, computerized tools cannot necessarily make equally important contributions to each stage. For example, an analysis of decisions to be made, which will continue to be the ultimate foundation of DSS development, will likely remain the purview of research specialists, management and systems analysts, and human dimensions scientists (although sometimes the analysis of decisions can be part of the DSS). On the other hand, more technologies are being developed that are proving useful in identifying problems, setting objectives, and facilitating group decisions. Information technologies, especially when coupled with the Internet, can make a successful contribution to intelligence gathering. Knowledge engineering, metadata development, and analysis of remotely sensed data fit this stage of the decision-making process.

When designing alternatives, the utility of advanced methods and technologies is often most apparent. Examples include statistical analysis, rule-based modeling, GIS, and Bayesian belief networks. The role of a DSS in evaluating decisions is often overlooked, although it clearly can make significant contributions. This is especially true in an adaptive management framework, where quantifying the value of new information is critical. A key concept in adaptive management is that new information affects the uncertainties associated with future alternatives.

\section{Framing the decision processes of natural resource managers}

Decision support systems can be useful for a variety of reasons. Klein (1998) identified three causes for "why good people make poor decisions": (1) they lack technical experience, (2) they lack information, and (3) they use inadequate mental simulation of possible scenarios. In addition to helping to remedy these three difficulties, a DSS can also assist with high volume or complicated computations (e.g., population viability analysis and hydrologic modeling).

The uncertainty associated with decision making, particularly with evaluating data, is another problem that can be addressed by a DSS. For example, when land managers must make choices about habitat manipulations, there invariably is uncertainty either about vegetation and wildlife parameters or about the ecological relationships affected by such manipulations. The effects of prescribed fire in native prairie on mallard (Anas platyrhynchos) nesting success may be well known in Stutsman County, North Dakota, but a biologist in the Rainwater Basin of Nebraska may be trying to decide whether to burn native grasses for bluewinged teal (Anas discors) nesting. When the uncertainty is primarily about the quality of information entered into the system, DSS should generate potential alternatives and recommend how to evaluate them. When the uncertainty is associated with the outcome of potential management actions, a system must generate and evaluate management options (Adelman, 1992). Finally, the issue being addressed by a manager can be so complex that no one individual can have a comprehensive view of, or even conceptualize, the whole problem or venue (Brehmer, 1991; Boland and others, 1992). For example, how does the need for winter food for lesser snow geese (Chen caerulescens) in the Central Valley of California relate to (1) quality and quantity of fall habitat at migration stopover sites in the Klamath Basin of Oregon; (2) gosling production at Wrangle Island, Alaska, or at Banks Island, Northwest Territories, during the previous summer; (3) early winter weather patterns on the Fraser River Delta, British Columbia; and (4) prevalence of avian disease in southern California? Ecological processes are inherently complex, and, therefore, so are many of the decisions resource managers must make.

Decision making in the everyday world tends to be influenced by at least eight factors (Orasanu and Connolly, 1993): (1) poorly defined problems; (2) uncertain, changing environments; (3) shifting, illdefined, or competing goals; (4) immediate actions that must occur before a decision can be formed; (5) highstress situations; (6) high stakes; (7) multiple people; and (8) organizational expectations. Consider, for example, how many or if all of these factors are in effect as a fisheries manager assembles the staff to discuss the potential benefits that will accrue from planting willows under differing spring weather scenarios to help stabilize the degraded banks of a creek. Or, consider how these eight factors describe the decision making environment that surrounds planning how much refuge staff time and budget will be necessary for inventorying piping plover (Charadrius 
melodus) reproduction this year. Almost every decision natural resource managers must consider is influenced by these factors. Only infrequently are natural resource managers faced with the isolated and incremental decisions that might typify some aspects of a manufacturing assembly line.

\section{Determining decision support systems needs}

Cleaves (1999) has delineated four questions that provide a valuable basis from which to design decision support systems:

- What decisions need support? Usually, a DSS, almost by definition, addresses poorly structured problems (Bonczek and others, 1981; Sprague and Carlson, 1982; Mallach, 1994; Holsapple and Whinston, 1996) or at least very complex problems (Carter and others, 1992). A different approach (Andriole, 1989) recommends applying a DSS to better defined and less complex problems to increase the probability of success. In any case, the decision to be supported must be clearly delineated.

- What parts of the decision-making process will be supported by the system?

- What kind of support is needed?

- How will the DSS fit into the decision-making process?

Useful DSS must result in one or more of the following outcomes. First, more effective decisions can be made that allow goals to be met, such as attaining population objectives, improving habitat conditions, or increasing the quality of monitoring data. Second, more efficient decisions can result, such as decisions requiring less time, fewer or lower ranking personnel, and the input of less data and information. Third, risk associated with future options can be estimated and thus might be decreased. Typically, such risk is lowered by decreasing the uncertainty associated with data, information, knowledge, and analyses upon which decisions are based. Low risk alternatives would minimize the chances of future catastrophes. Fourth, an increase in the ability to understand complex decision frameworks can result, along with an accompanying ability to explain management decisions to stakeholders.

Carter and others (1992) provide a slightly different perspective on DSS. They state that good systems minimize the probabilities of four things: (1) making a poor decision, (2) missing a good alternative, (3) making a decision at a bad time, or (4) focusing on the wrong problem.
Launching the research and development process Numerous variations exist for developing a DSS (see table 1). Based on a review of this information, we recommend the following DSS research and development process, which recognizes the various stages of the decision-making process described previously (see Decision Process as a Component of DSS Development section). It also recognizes a distinction between decision making itself and development of DSS to support those decisions.

1. a. Evaluate the existing decision-making process used by managers that might benefit from decision support (i.e., intelligence gathering). Formulate one or more testable hypotheses about where and how decision support would be useful in particular venues, recognizing that a DSS should address poorly defined problems. $E x$ ample: Identify formal policies, individual values, available information, computerized tools, professional networks, and other considerations that might assist or constrain a forest supervisor's decision to close or open logging roads for motorized recreation.

b. Conduct research that will guide development of specific decision support tools by defining the decision-making process of management users. Example: A park biologist might want to assess potential effects of campground development on riparian sites. Identify the process used by the biologist to determine the value of riparian habitat values and how that process could be improved with decision support tools.

2. Use state-of-the-art technologies, operations research, and management methods for building and delivering decision support systems. $E x$ ample: Constraint satisfaction programming methods (see glossary) have been used to provide guidance for managers on how to manage seasonal wetlands for certain moist soil characteristics (see http://www.mesc.usgs.gov/msma/).

3. Implement decision support tools, iteratively conducting validation and verification. Example: During development of a DSS for trumpeter swan (Cygnus buccinator) management, early versions were made accessible via the World Wide Web to managers and biologists to gain their input about the reliability of contributed data (see http://swan.msu.montana.edu/cygnet).

4. Evaluate decision support tools by testing previously developed hypotheses. Was the research able to accurately predict where and how such tools would be helpful to managers in making decisions? Did more effective or efficient decisions result? Example: Maybe we hypothesized 
Table 1. Various approaches to DSS development and application.

\begin{tabular}{|c|c|c|c|c|c|}
\hline Andriole (1989) & Carter et al. (1992) & Finlay (1994) & Sage (1991) & $\begin{array}{l}\text { Sprague and } \\
\text { Carlson (1982) }\end{array}$ & $\begin{array}{l}\text { Stuth and } \\
\text { Smith (1993) } \\
\end{array}$ \\
\hline $\begin{array}{l}\text { Requirements } \\
\text { analysis }\end{array}$ & System definition & Feasibility & $\begin{array}{l}\text { Requirements } \\
\text { specification }\end{array}$ & $\begin{array}{l}\text { Subproblem } \\
\text { identification }\end{array}$ & $\begin{array}{l}\text { Broad } \\
\text { requirements } \\
\text { specification }\end{array}$ \\
\hline $\begin{array}{l}\text { Modeling (of the } \\
\text { system itself) }\end{array}$ & $\begin{array}{l}\text { Iterative } \\
\text { development }\end{array}$ & Analysis & $\begin{array}{l}\text { Preliminary } \\
\text { conceptual } \\
\text { design }\end{array}$ & $\begin{array}{l}\text { Small but } \\
\text { usable system } \\
\text { development }\end{array}$ & $\begin{array}{l}\text { Prototype } \\
\text { development }\end{array}$ \\
\hline $\begin{array}{l}\text { Methods } \\
\text { selection }\end{array}$ & $\begin{array}{l}\text { Continual } \\
\text { implementation } \\
\text { and maintenance }\end{array}$ & Design & $\begin{array}{l}\text { Detailed design, } \\
\text { testing, and } \\
\text { implementation }\end{array}$ & $\begin{array}{l}\text { Cyclical } \\
\text { refinement, } \\
\text { expansion, and } \\
\text { modification of } \\
\text { the system }\end{array}$ & $\begin{array}{l}\text { Prototype } \\
\text { testing }\end{array}$ \\
\hline $\begin{array}{l}\text { Software } \\
\text { selection/design }\end{array}$ & & Programming & $\begin{array}{l}\text { Operational test } \\
\text { and evaluation }\end{array}$ & $\begin{array}{l}\text { Constant } \\
\text { evaluation }\end{array}$ & $\begin{array}{l}\text { Detailed } \\
\text { specification }\end{array}$ \\
\hline $\begin{array}{l}\text { Hardware } \\
\text { selection/design }\end{array}$ & & Testing & $\begin{array}{l}\text { Operational } \\
\text { deployment }\end{array}$ & & $\begin{array}{l}\text { Pilot system } \\
\text { design and } \\
\text { implementation }\end{array}$ \\
\hline System packaging & & Documentation & & & Field trials \\
\hline System transfer & & Implementation & & & $\begin{array}{l}\text { Evaluation and } \\
\text { iteration }\end{array}$ \\
\hline Evaluation & & Review/ evaluation & & & $\begin{array}{l}\text { Operational } \\
\text { systems design } \\
\text { and } \\
\text { implementation }\end{array}$ \\
\hline \multirow[t]{4}{*}{ Feedback } & & Maintenance & & & $\begin{array}{l}\text { Operational } \\
\text { use and } \\
\text { feedback }\end{array}$ \\
\hline & & & & & $\begin{array}{l}\text { User support, } \\
\text { review, and } \\
\text { iteration }\end{array}$ \\
\hline & & & & & $\begin{array}{l}\text { Evolutionary } \\
\text { development }\end{array}$ \\
\hline & & & & & Widening use \\
\hline
\end{tabular}

${ }^{1}$ Each of these steps is further subdivided into 6-21 substeps.

${ }^{2}$ The authors credit Eason (1988); their process is not necessarily linear.

that habitat acquisition biologists needed an expert system and GIS combination to assess in what specific areas the greatest benefit would accrue from their efforts to acquire wetland habitat. Did the system that was provided lead to recommendations that, when implemented, resulted in a stabilization of waterfowl, rail (Family Rallidae), and shorebird numbers in a county where they had earlier been decreasing?

5. Institutionalization of the DSS enterprise throughout the organization (e.g., budget, staff, organizational buy in and oversight, coordination, information and technology transfer, support, etc.).

\section{Developing software: evolutionary prototyping}

We recommend the use of evolutionary prototyping for DSS development (Sprague and Carlson, 1982; Carter and others, 1992). This is a step-by-step process that integrates planning, developing, validating, delivering, and supporting software systems and is based on extensively involving users throughout. It can be 
thought of as focusing on the development of an early prototype, even during the planning stages, and then continually refining it to its eventual implementation. Our overall recommended process for DSS development is summarized in figure 1.

\section{Evaluating DSS development efforts - the need for verification and validation}

Why should one evaluate decision support systems and expert systems? The answer is, quite simply, to increase the probability that they will be used and effective (Adelman, Evaluating Decision Support and Expert Systems, 1992).

The scientific literature is particularly devoid of work on the evaluation of decision support systems. This can be traced, at least partially, to problems associated with verification and validation of such complex software systems. On the other hand, much can be learned by examining the analogous, and fairly rich literature on verification and validation of expert systems and other artificial intelligence methods, which are quite often types of decision support systems (see Cohen and Howe, 1989; Bahill, 1991; Grogono and others, 1991; Gupta, 1991; Hamilton and others, 1991; Adelman, 1992; O’Leary, 1994).

\section{Verification and validation}

Wallace and Fujii (1989) define verification and validation of software as analysis and testing "to determine that [the software] performs its intended functions correctly, to ensure that it performs no unintended functions, and to measure its quality and reliability." Verification and validation are often considered together under the heading of evaluation. Evaluation should be part of the development process, and evaluators should specifically be part of the development team (Adelman, 1992).

"Verification" means ensuring that the system is internally complete, coherent, and logical, essentially from a modeling and programming perspective. "Validation" means examining whether the system is accurate, realistic, and useful to the user or decision maker (Geissman and Schultz, 1988). O'Keefe and others (1987) state: "Validation means building the right system. Verification means building the system right."

For example, national park biologists might be interested in a system that helps them design water quality monitoring schemes for spring-fed streams to determine appropriate road improvement procedures. Verification might involve ensuring that the system will access the correct data and that the graphical results will be of the same statistical precision and accuracy as represented in the textual presentation. Validation might check that the system is reporting those figures in a fashion usable by the biologist, likely requiring explanation of the tests used and why they are appropriate. More importantly, validation would ensure that the correct monitoring parameters are used to help the park make the determinations that they need regarding road improvements.

\section{An overview of methods}

Following Adelman (1992), successful implementation of decision support and expert systems hinges on incorporating three evaluation procedures: (1) those that examine the logical consistency of the system algorithms themselves (verification), (2) those that empirically test the predictive (or ecological) accuracy and effectiveness of the system (validation), and (3) those that document user satisfaction and meet user needs.

Stuth and Smith (1993) followed the ideas of Eason (1988) and recommend iterative prototyping methods for DSS development. When using such methods, verification and validation are part of the iterative process of system development. Verification should be performed at the stage prior to delivery of a working system to users, even if only a prototype system. General validation might be done at this stage as well, with more detailed efforts performed once an operating system is delivered. If one subscribes to the concept that software development can be a dynamic process, then verification and validation are vital parts of that continued process which seeks regular refinements (Carter and others, 1992; Stuth and Smith, 1993).

Sprague and Carlson (1982) recommend that organizations building their first DSS recognize that it is essentially a research activity and that evaluation should center on a general value analysis as defined by Keen (1981). This consists of four steps: (1) identify the potential benefits, (2) determine the maximum cost allowable for development, (3) develop a prototype, and (4) determine the benefits in relation to costs. They state that iterative prototyping will ensure a quality product from the managers' perspectives but recognize the qualitative nature of such evaluation. It is imperative that analytic and quantitative rigor be added beyond the "soft testimonials" often seen (Andriole, 1989; Cohen and Howe, 1989). Sensitivity analysis can be a powerful tool for validation, especially for heuristic-based systems and for systems where few or no test cases are 


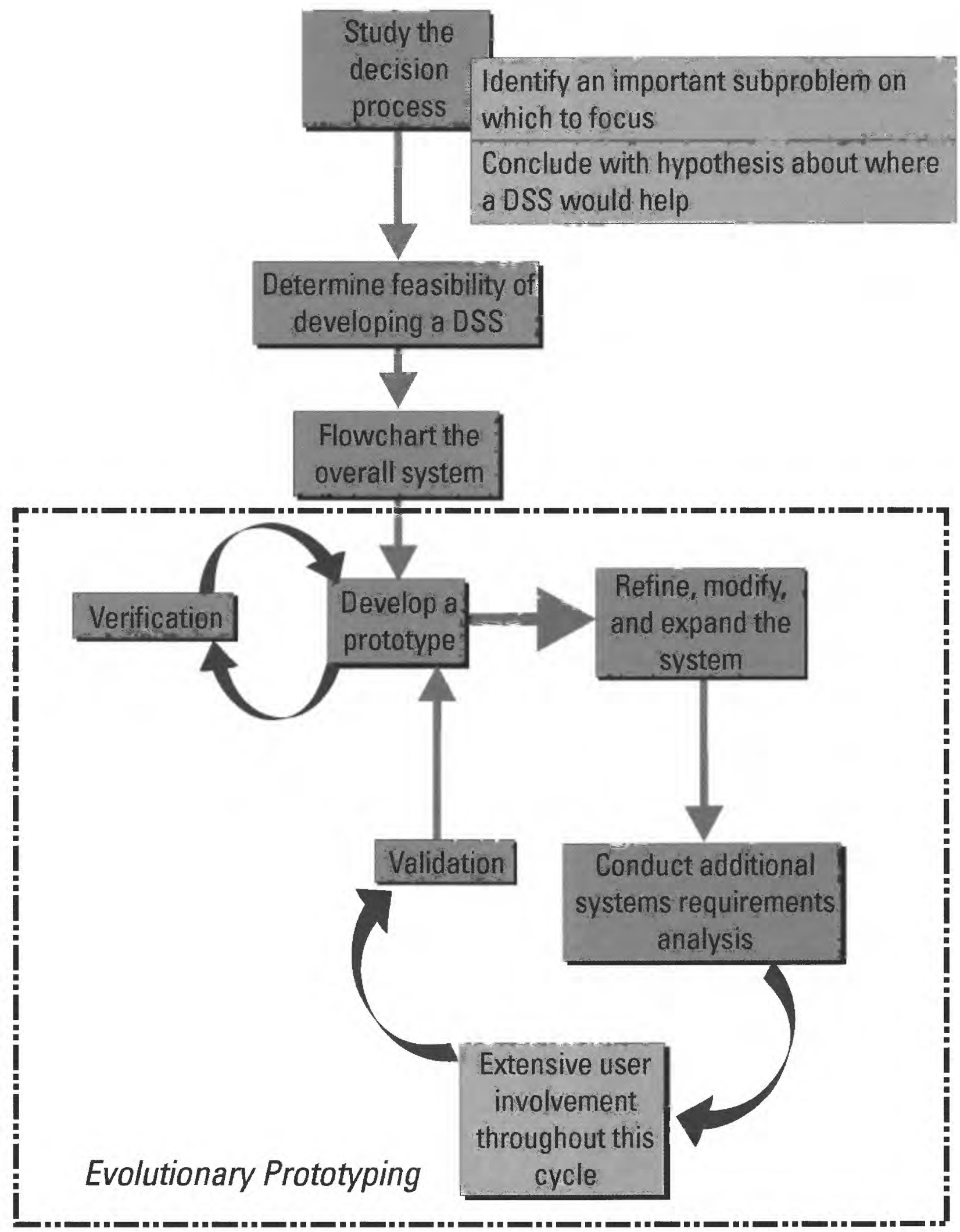

Figure 1. A recommended process for decision support system development. 
available for comparison (O'Keefe and others, 1987; Bahill, 1991). Another issue suggested by Rushby (1991) is that it is necessary to show not only how well a system performs but also to show that it can avoid making a catastrophic recommendation. This feature is important in many natural resource venues because of the great concern for long-term, irretrievable ecological changes.

Consider, for example, the sensitive issues associated with determining the impact of dredging on mussels in a watershed. Obviously, a DSS trying to support such decisions needs to maximize the opportunities for maintaining healthy mussel populations. However, doing so might increase the probability of a catastrophic response in the mussel population should some dynamic environmental variable rapidly change. Is the DSS capable of handling the scenario of a 500-year-frequency flood event's impact on mussels? For a species whose population is endangered, such as the dwarf wedge mussel (Alasmidonta heterodon), this can be a critical question.

For many reasons, verification and validation of knowledge-based and other decision support systems are more problematic than for other modeling efforts (Gupta, 1991). Under some conditions, modeling research can test performance against a preselected standard. With natural resource issues, such a standard often does not exist. This is particularly true with near real-time decision support that is expected to predict and guide future scenarios while those scenarios are, in fact, unfolding. Also, not only should a system handle the most common cases, but it ought to also be able to model extreme events as well. Extreme events are not only common in, but often have profound effects on ecological systems. For example, many habitats throughout North America maintain their diagnostic characteristics through a dependence upon fire. In cases such as tallgrass prairie, fires may be thought of as a common occurrence, and this type of event can be replicated in a DSS somewhat straightforwardly. But what happens in other places, such as the Northern Rockies, where the time elapsed between fires may be many decades or longer? In addition to being equipped to address "normal" conditions, a DSS for such situations must be versatile enough to simulate various fire regimes and the probabilities associated with ideal conditions and all other possibilities, and flexible enough to handle sudden corrections when an unexpected drought or wet period alters fire potentials beyond what was anticipated. Designing formal evaluations to ensure DSS are powerful and dynamic is difficult.

It is sometimes possible to test expert system performance against an independent panel of experts
(O'Keefe and others, 1987). Two concerns must be addressed, however. First, the panel of experts needed for such an evaluation must not be the same people who were connected to system development itself, or confounding effects could be introduced that would prevent reasonable experimental design. Second, one of the basic tenets of using a DSS for complex issues is that such questions are beyond the capability of individuals to conceptualize and solve (Brehmer, 1991; Boland and others, 1992).

Wallace and Fujii (1989) provide a comprehensive matrix of 41 techniques and tools that can be applied to 10 verification and validation issues. Cohen and Howe (1989) take a slightly different approach but also discuss evaluation from the perspective of the software development life cycle. Their emphasis is on empirical studies to accomplish such evaluation, whether one is focusing on verification or validation. Specifically for knowledge-based systems, Murrell and Plant (1997) provide a categorization of 145 different automated techniques for testing such systems.

\section{Recommended procedures}

The following eight general steps should be used for verification (Geissman and Schultz, 1988; Cohen and Howe, 1989; Wallace and Fujii, 1989; Grogono and others, 1991; Sage, 1991; Adelman, 1992; Finlay, 1994). Whenever possible, experimental testing of the complete system, or components thereof, should be performed.

1. Examine the high-level (overall system) design.

- Are all requirements covered, and are they broken down into reasonable components?

- Are any components redundant?

- Do individual components request appropriate inputs and deliver correct outputs?

- Are uncertainties propagated correctly among components?

2. Examine each component to ensure that it carries out what is requested by the high-level design.

- Is there logical consistency within models, rules, knowledge, information, and data?

- Does redundancy exist within models, rules, knowledge, information, and data?

- Are uncertainties propagated correctly within individual modules?

3. Ensure that all computer code conforms to standard style and documentation.

4. Ensure that all system programs compile and operate without errors.

5. Determine if the system is complete enough to cover all realistic parameters and situations. 
6. Survey the users about user-friendliness of the system.

- Does the user interface function as intended?

- Are questions asked by the system understandable?

- Is the output understandable?

- Are there any annoyances to the user in the system?

7. Document metadata for the system and related databases.

8. Ensure that the most appropriate data for the system are used.

For validation, empirical testing of a DSS using sound, experimental research methods is always best. Whole system testing and individual component testing are both necessary. Again, the work of Geissman and Schultz (1988), Cohen and Howe (1989), Wallace and Fujii (1989), Grogono and others (1991), Sage (1991), Adelman (1992), and Finlay (1994) all provide insights into empirical methods appropriate for validation. Suggesting specific steps to follow for system validation is difficult because system performance must be measured in terms of how the decision-making process has been affected, and often the process may have evolved since the start of the project. However, at least nine considerations are important for validation:

1. Determine if each module or component makes a contribution to improving the decision maker's performance.

2. Assess whether each module accurately and with minimum bias provides an assessment of the uncertainty associated with the module output.

3. Evaluate whether individual modules represent realistic descriptions of their respective environments as well as average and extreme cases.

4. Assess whether the system provides a realistic ecological understanding and natural resource management perspective. How does the overall system deal with average cases as well as with extreme cases?

5. Make certain assumptions and constraints of the system are clear to the user.

6. Prior to beginning system development, generate expectations of how the completed system will affect decision performance. Design evaluation processes to test those hypotheses.

7. Conduct empirical user satisfaction studies.

8. Evaluate flexibility of the system to respond to changing user requirements.

9. Determine the reliability of measures to avoid ecologically catastrophic recommendations.

\section{Summary}

This document presented a broad range of concepts, issues, and recommendations related to the need for and the development and use of decision support systems. We hope that it will be useful to managers and decision makers, as well as potential developers, implementers, and others generally interested in the subject of DSS. A DSS was generally defined as an interactive, computerbased tool or collection of tools that use(s) information and models to improve the process and outcome of decision making. The characteristics and capabilities of DSS were discussed-what a DSS is and is not. We also caution that it is easy to develop unrealistic expectations of a DSS, and it should be understood that a DSS is not designed to replace decision makers, nor will it eliminate poor decisions.

The importance of meeting resource manager's needs and other customer requirements was emphasized, as was the need to develop systems that provide support for specific applications. Providing a DSS that has the desired capabilities but is not usable by the manager is, at best, a wasted effort and at worst it can discourage managers from use of DSS in the future. The reverse situation (i.e., a DSS easily used by managers but does not have the capabilities to meet application needs) is also just as detrimental. We explain why information and technology transfer, user support, and other matters related to institutionalization of DSS are issues that need to be addressed in order to achieve successful long-term development, implementation, and use of DSS.

A description of the stages in the decision-making process is presented, as is how this process should aid in framing the decision process of natural resource managers and determining DSS needs. Although numerous approaches for developing a DSS exist, we recommend a DSS research and development process that recognizes the various stages of the decisionmaking process and incorporates evolutionary prototyping.

We stress the need for validation and verification when evaluating DSS development efforts. An overview of validation and verification methods is presented, and several steps and considerations are recommend for performing validation and verification of a DSS. The ultimate goals related to the validation and verification of decision support systems are to "build the right systems and build the systems right." 
For those who want additional information about various aspects of DSS, such as the decision process, collaborative tools for decision support, information management and interoperability, knowledge management and decision support, and computation, communication, and data storage, see Appendix 2 ("Decision Support Capabilities for Future Technology Requirements," edited by Gene Lessard).

\section{Acknowledgments}

We would like to thank those who provided input to the USGS Decision Support Systems Special Interest Group (DSSSIG) questionnaire, those who gave presentations, and those who participated in the 1998 USGS Biological Resources Division DSS Workshop, "Development of Biological Decision Support Systems for Resource Managers." We would also like to thank Jim Getter and Tom Gunther for their efforts related to the development of the workshop and this document. Lastly, we want to thank the peer reviewers, who made valuable suggestions on ways to improve this document.

\section{References cited}

Adelman, L., 1992, Evaluating decision support and expert systems: New York, N.Y., John Wiley and Sons, Inc., $232 \mathrm{p}$.

Alter, S., 1978, Development patterns for decision support systems: MIS Quarterly, v. 2, no. 3, p. 33-42.

Andriole, S.J., 1989, Handbook of decision support systems: Blue Ridge Summit, Penn., TAB Professional and Reference Books, $248 \mathrm{p}$.

Bahill, T.A., 1991, Verifying and validating personal computer-based expert systems: Englewood Cliffs, N.J., Prentice-Hall, Inc., 205 p.

Biddle, P.B., Cross, D.H., Jennings, D.P., Sojda, R.S., and Solomon, R.C., 1995, Information needs and technology applications of Department of the Interior natural resource professionals: Wildlife Society Bulletin, v. 23, no. 4, p. 627-630.

Boland, R.J., Mahewshwari, A.K., Te'eni, D., Schwartz, D.G., and Tenkasi, R.V., 1992, Sharing perspectives in distributed decision making, in Proceedings of the Conference on Computer-Supported Cooperative Work: New York, N.Y., Association for Computing Machinery, p. 306-313.
Bonczek, R.H., Holsapple, C.W., and Whinston, A.B., 1981, Foundations of decision support systems: New York, N.Y., Academic Press, 393 p.

Brehmer, B., 1991, Distributed decision making: some notes on the literature, in Rasmussen, J., Brehmer, B., and Leplat, J., eds., Distributed decision making: cognitive models for cooperative work: Chichester, England, John Wiley and Sons, p. 3-14.

Brimicombe, A., 1992, Flood risk assessment using spatial decision support systems: Simulation, v. 59, no. 6 , p. 379-380.

Carter, G.M., Murray, M.P., Walker, R.G., and Walker, W.E., 1992, Building organizational decision support systems: San Diego, Calif., Economic Press Inc., 358 p.

Cleaves, D., 1999, Supporting the decision process: what can we hope for and expect from DSS's? in Report on the Decision Support Systems Workshop, Feb. 18-20, 1998, Denver, Colo.: U.S. Geological Survey Open-File Report 99-351, 120 p.

Cohen, P.R., and Howe, A.E., 1989, Toward AI research methodology: three case studies in evaluation, IEEE Transactions on Systems, Man, and Cybernetics, v. 19, no. 3, p. 634-646.

Eason, K., 1988, Information technology and organizational change: London, U.K., Taylor and Francis Publishing, $247 \mathrm{p}$.

Finlay, P., 1994, Introducing decision support systems: Cambridge, Mass., Blackwell Publishers, 274 p.

Geissman, J.R., and Schultz, R.D., 1988, Verification and validation of expert systems: AI Expert, v. 3, no. 2, p. 26-33.

Getter, J., D’Erchia, T., and Root, R., eds., 1999, Proceedings of the workshop "Development of biological decision support systems for resource managers," Denver, Colo., October 27-29, 1998: Denver, Colo., U.S. Geological Survey, Biological Resources Division, Information and Technology Report USGS/BRD/ITRB2000-0002, v + 41 p.

Grogono, P., Batarekh, A., Preece, A., Shinghal, R., and Suen, C., 1991, Expert system evaluation: a selected bibliography: Expert Systems, v. 8, no. 4, p. 227239.

Gunther, T., 1998, Decision support systems tools, services and systems, World Wide Web, http:// biology.usgs.gov/dss/gunther/index.html.

Gupta, U., 1991, Validating and verifying knowledgebased systems: Washington, D.C., IEEE Computer Society Press, $423 \mathrm{p}$.

Hamilton, D., Kelley, K., and Culbert, C., 1991, Stateof-the-art practice in knowledge-based system verification and validation: Expert Systems with Applications, v. 3, p. 403-410. 
Holsapple, C.W., and Whinston, A.B., 1996, Decision support systems: a knowledge-based approach: St. Paul, Minn., West Publishing Co., 713 p.

Jensen, F.V., 1996, An introduction to Bayesian networks: New York, N.Y., Springer Verlag, 178 p.

Keen, P.G.W., 1981, Value analysis: justifying decision support systems: Management Information System Quarterly, v. 5, no. 1, p. 1-16.

Kimball, R., 1996, The data warehouse toolkit: practical techniques for building dimensional data warehouses: New York, N.Y., John Wiley and Sons, Inc.

Klein, G., 1998, Sources of power: how people make decisions: Cambridge, Mass., MIT Press, $330 \mathrm{p}$.

Lessard, G., and Gunther, T., eds., 1998, Report on the decision support systems workshop, Denver, Colo., February 18-20, 1998: Reston, Va., U.S. Department of the Interior, U.S. Geological Survey, Open File Report 99-351, 120 p.

Mallach, E.G., 1994, Understanding decision support systems and expert systems: Boston, Mass., Richard D. Irwin, Inc., 695 p.

Murrell, S., and Plant, R.T., 1997, A survey of tools for the validation and verification of knowledge-based systems: 1985-1995: Decision Support Systems, v. 21, p. 307-323.

O'Keefe, R.M., Balci, O., and Smith, E.P., 1987, Validating expert system performance: IEEE Expert, v. 2 , no. 4 , p. $81-90$.

O'Leary, D.E., 1994, Verification and validation of intelligent systems: five years of AAAI workshops: International Journal of Intelligent Systems, v. 9, p. 653-657.

Orasanu, J., and Connolly, T., 1993, The reinvention of decision making, in Klein, G.A., Orasanu, J., Calderwood, R., and Zsambok, C.E., eds., Decision making in action: models and methods: Norwood, N.J., Ablex Publishing Corp., 480 p.

Parker, M.M., Trainor, H.H., and Benson, R.J., 1989, Information strategy and economics: Englewood Cliffs, N.J., Prentice Hall.

Pearl, J., 1988, Probabilistic reasoning in intelligent systems: networks of plausible inference: San Mateo, Calif., Morgan Kaufmann Publishers, 552 p.

Power, D.J., and Kaparthi, S., 1998, The changing technological context of decisions support systems, in Berkeley, D., Widmeyer, G., and Brezillon V, P., eds., Context-sensitive decision support systems: Chapman and Hall, p. 41-54.

Rushby, J., 1991, Validation and testing of knowledgebased systems: how bad can it get? in Gupta, U., ed., Validating and verifying knowledge-based systems:
Washington, D.C., IEEE Computer Society Press, p. 77-83.

Sage, A.P., 1991, Decision support systems engineering: New York, N.Y., John Wiley and Sons, Inc., 344 p.

Simon, H.A., 1960, The new science of management decision: New York, N.Y., Harper and Brothers Publishers, $50 \mathrm{p}$.

Sprague, R.H., Jr., and Carlson, E.D., 1982, Building effective decision support systems: Englewood Cliffs, N.J., Prentice-Hall, 329 p.

Stuth, J.W., and Smith, M.S., 1993, Decision support for grazing lands: an overview, in Stuth, J.W., and Lyons, B.G., eds., Decision support systems for the management of grazing lands: Pearl River, N.Y., Parthenon Publishing Group, p. 1-35.

Turban, E., 1990, Decision support systems and expert systems, (2nd ed.): New York, N.Y., Macmillan.

U.S. Geological Survey, Biological Resources Division, 1996, Biological Resources Division strategic plan: World Wide Web, biology.usgs.gov/science/ strategicplan.html.

Wallace, D.R., and Fujii, R.U., 1989, Software verification and validation: an overview: IEEE Software, v. 6 , no. 3 , p. 10-17.

\section{Decision support systems glossary}

The glossary is used with permission from Power, D.J., 1999, Decision Support Systems Glossary, Decision Support Systems Resources: World Wide Web http://DSSResources.com/glossary accessed on 9 May 2001. Words preceded by an asterisk have been added by the authors of this document.

Ad-Hoc Query - Any spontaneous or unplanned question or query. It is a query that consists of dynamically constructed SQL, which is usually constructed by desktop-resident query tools.

Ad-Hoc Query Tool - An end-user tool that accepts an English-like or point-and-click request for data and constructs an ad-hoc query to retrieve the desired data from a database.

Agents - Self-contained processes that run in the background on a client or server and that perform useful functions for a specific user/owner. Agents may monitor exceptions based on criteria or execute automated tasks. For example, once an event occurs a daemon performs a pre-defined action and then it returns to a monitoring state. See demon or daemon. 
Aggregate or Aggregated Data - Data that result from applying a process to combine data elements. Data that are summarized.

Alerts - A notification from an event that a trigger has exceeded a predefined threshold. See agents.

Analytical Hierarchy Process - An approach to decision making that involves structuring multiple choice criteria into a hierarchy, assessing the relative importance of these criteria, comparing alternatives for each criterion, and determining an overall ranking of the alternatives.

*Bayesian Belief Network - A Bayesian belief network is a graphical model of a problem that represents causal relations and is used for calculating probability distributions of unobserved variables given the observed variables. For a more detailed treatment, see Jensen (1996) and Pearl (1988).

Business Data - Data about people, places, things, business rules, and events used to operate a business. It is not metadata.

Business Intelligence - BI is a popularized, umbrella term introduced by Howard Dresner of the Gartner Group in 1989 to describe a set of concepts and methods to improve business decision making by using fact-based support systems. The term is sometimes used interchangeably with briefing books and executive information systems. A business intelligence system is a DSS.

Business Model - In a data warehouse it is the designer's view of how the business functions. The view can be from a process, data, event, or resource perspective and can be the past, present, or future state of the business.

Business Transaction - According to Microstrategy, it is a unit of work acted upon by a data capture system to create, modify, or delete business data. Each transaction represents a single valued fact describing a single business event.

Client/Server Architecture - A network architecture in which computers on a network act as a server managing files and network services OR as a client where users run applications and access servers. Clients rely on servers for resources like web pages, data, files, printing, and On-line Analytical Processing (OLAP).

Cognitive Overload - A psychological phenomenon characterized by an overload of information for a decision maker. The amount of information exceeds the person's cognitive capacity. DSS can reduce or increase cognitive overload.

Computer-Mediated Communication - The use of computers to create, store, deliver, and process communications.
Computer Supported Cooperative Work - The use of computers to support cooperative work among multiple participants (e.g., collaborative authoring), as distinct from work that may not be cooperative.

Conferencing, Videoconferencing or Teleconferencing - Real-time, two-way communications. Audiovideo telecommunication support of simultaneous interactions among participants (e.g., involving conference calls or videoconferencing).

* Constraint Satisfaction Programming - A method for solving a set of mathematical problems which uses the process of assigning values to variables while meeting certain requirements or "constraints." It is a form of artificial intelligence that is often used in the field of optimization. Some common uses are scheduling, manufacturing, and planning. It has a number of benefits (mainly flexibility) over other common approaches to these problems, like linear programming.

Controllable Variables - Decision variables that can be changed and manipulated by a decision maker, such as quantity to produce, amount of resources to allocate, etc.

Corporate Planning System - A decision support system that holds and derives knowledge relevant to planning decisions that cut across organizational units and involve all of an organization's functions (i.e., its operations, finance, marketing, personnel, etc.).

Critical Success Factors - Key areas of business activity in which favorable results are necessary for a company to reach its goals.

Data - Binary (digital) representations of atomic facts, text, graphics, bit-mapped images, sound, analog or digital live-video segments. Data is the raw material of a system supplied by data producers and is used by information consumers to create information.

Data Conferencing - This term refers to a communication session in which two or more participants are sharing computer-based data in real-time. Any participants' keyboard/mouse can control screens of other participants. Voice communication can be outof-band using a totally separate voice connection or in-band using a simultaneous voice and data technology.

Data Dictionary - A database about data and database structures. A catalog of all data elements, containing their names, structures, and information about their usage. A central location for metadata. Normally, data dictionaries are designed to store a limited set of available metadata, concentrating on the information relating to the data elements, databases, files and programs of implemented systems. 
Data-Driven DSS or Data-Oriented DSS - This type of DSS emphasizes access to and manipulation of a time-series of internal company data and sometimes external data. Simple file systems accessed by query and retrieval tools provide the most elementary level of functionality. Data warehouse systems that allow the manipulation of data by computerized tools tailored to a specific task and setting or by more general tools and operators provide additional functionality. Data-driven DSS with OLAP or data mining tools provide the highest level of functionality and decision support that is linked to analysis of large collections of historical data. Early, very limited versions of data-driven DSS were called Retrieval-Only DSS by Bonczek and others (1981).

Data Element - The most elementary unit of data that can be identified and described in a dictionary or repository which cannot be subdivided.

Data Mining - A class of analytical applications that search for hidden patterns in a data base. Data mining is the process of sifting through large amounts of data to produce data content relationships. This is also known as data surfing. Data mining tools use a variety of techniques including case-based reasoning, data visualization, fuzzy query and analysis, and neural networks. Case-based reasoning tools provide a means to find records similar to a specified record or records. These tools let the user specify the "similarity" of retrieved records. Data visualization tools let the user easily and quickly view graphical displays of information from different perspectives.

Data Quality - High quality data is accurate, timely, meaningful, and complete. DSS must have high quality data; low quality data can result in bad decisions. Assessing or measuring data quality is a preliminary task associated with evaluating the feasibility of a data-driven DSS project.

Data Warehouse - A database designed to support decision making in organizations. It is batch updated and structured for rapid online queries and managerial summaries. Data warehouses contain large amounts of data. A data warehouse is a subjectoriented, integrated, time-variant, nonvolatile collection of data in support of management's decision making process. Check "What is a Data Warehouse" by W.H. Inmon at http:// www.cait.wustl.edu/cait/papers/prism/vol1_no1/. According to Kimball (1996), "a data warehouse is a copy of transaction data specifically structured for query and analysis" (see "A Definition of Data Warehousing" by I. Greenfield at http:// pwp.starnetinc.com/larryg/defined.html.)
Data Visualization - This term refers to presenting data and summary information using graphics, animation, 3-D displays, and other multimedia DSS tools.

Decision - The choice of one from among a number of alternatives; a statement indicating a commitment to a specific course of action.

Decision Analysis Tools - DA tools help decision makers decompose and structure problems. The aim of these tools is to help a user apply models like decision trees, multi-attribute utility models, Bayesian models, Analytical Hierarchy Process (AHP), etc. Examples of DA software packages include AliahThink, BestChoice3, Criterium Decision Plus, DecideRight, DecisionMaker, Demos, DPL, Expert Choice, Strad, Supertree, and Which and Why.

Decision Room - A physical arrangement for a group DSS in which workstations are available to participants. The objective for using a Decision Room is to enhance and improve the group's decision-making process.

Decision Systems are computer based programs and technologies intended to make routine decisions, monitor and control processes, and aid or assist decision makers in semi-structured and/or nonroutine decision situations.

Decision Support Systems (DSS) are interactive computer-based systems intended to help decision makers utilize data and models to identify and solve problems and make decisions. The "system must aid a decision maker in solving unprogrammed, unstructured (or 'semistructured') problems...the system must possess an interactive query facility, with a query language that ...is ...easy to learn and use" (Bonczek and others, 1981:19). DSS help managers/ decision makers use and manipulate data; apply checklists and heuristics; and build and use mathematical models. According to Turban (1990), a DSS has four major characteristics: DSS incorporate both data and models; they are designed to assist managers in their decision processes in semistructured (or unstructured) tasks; they support, rather than replace, managerial judgment; and their objective is to improve the effectiveness of the decisions, not the efficiency with which decisions are being made.

Decision Variables - In a model-driven DSS a decision variable is a changing factor in the model that is determined by a decision maker. They are sometimes called independent variables, and the range of values for the decision variables constrain the choices of the decision maker.

Demon or Daemon - A computer program or procedure that is automatically activated when it recognizes a specific, predefined state or condition. 
Descriptive Model - Physical, conceptual, or mathematical models that describe situations as they are or as they actually appear.

Deterministic Model - Mathematical models that are constructed for a condition of assumed certainty. The models assume there is only one possible result (which is known) for each alternative course or action.

Development Environment - The DE is used by a designer/builder. A development environment typically includes software for creating and maintaining a knowledge base and software for the inference engine.

Dialog Generation and Management System (DGMS) - A software management package in a DSS whose functions in the dialog subsystem is similar to that of a DBMS in a database (see Sprague and Carlson, 1982).

Dialog System - The hardware and software that create and implement a user interface for a DSS. A DSS dialog system creates the human-computer interface.

Domain Expert - A person who has expertise in the domain in which a specific expert system is being developed. A domain expert works closely with a developer (known as a knowledge engineer) to capture the expert's knowledge (especially rule and relationship information) in a computer readable representation often called a knowledge base.

Drill Down/Up - An analytical technique that lets a DSS user navigate among levels of data ranging from the most summarized (up) to the most detailed (down).

DSS Generator - Computer software package that provides tools and capabilities that help a developer quickly and easily build a specific Decision Support System (see Sprague and Carlson, 1982:11). Excel is an example of a DSS Generator. Many companies market tools for building DSS and EIS.

DSS Development Tools - Software components (such as editors, code libraries, specific objects, visual interfaces) that facilitate the development of a specific DSS.

e-Meetings - A term for a meeting supported by fullmotion video, audio, and web meeting tools. One or more participants in the meeting is participating remotely in the meeting. It is possible that all participants are in different physical locations.

Enterprise-wide DSS - A DSS that supports a large group of managers in a networked client-server environment with a specialized data warehouse as part of the DSS architecture.

Evolutionary (Iterative) Design Process - A systematic process for system development that is recommended for use in creating DSS. A portion of the
DSS system is quickly constructed, then tested, improved, and enlarged in systematic steps. This methodology is similar to prototyping.

Exception Reporting - A reporting philosophy and approach that supports Management by Exception. Reports should be designed to display significant exceptions in results and data. The idea is to "flag" important information and bring it quickly to the attention of managerial users of the report. Exception reporting can be implemented in any type of DSS, but it is particularly useful in data-driven DSS and EIS.

Executive Information Systems (EIS) - A computerized system intended to provide current and appropriate information to support executive decision making for managers using a networked workstation. The emphasis is on graphical displays and an easy to use interface that present information from the corporate database. They are tools to provide canned reports or briefing books to top-level executives. They offer strong reporting and drill-down capabilities.

Executive Support Systems (ESS) - An executive information system (EIS) that includes specific decision aiding and/or analysis capabilities.

Expert Systems - Are man-machine systems with specialized problem-solving expertise. The "expertise" consists of knowledge about a particular domain, understanding of problems within that domain, and "skill" at solving some of these problems.

Facilitator - A person(s) who manages the use of a group decision support system from initial planning through actual operation.

Feasibility Study - A study of the technical and economic prospects for developing a system prior to actually committing resources to actually developing it.

Functional DSS - A decision support system that holds and derives knowledge relevant for decisions about some function an organization performs (e.g., a marketing function, a production function).

Generators - Software packages that are designed to expedite programming efforts that are required to build information systems, especially expert and decision support systems.

Goal-seeking - The capability of asking the computer software what values certain variables must have in order to attain desired goals. It is a tool that uses iterative calculations to find the value required in one cell (variable) in order to achieve a desired value in another cell. A common use of the goal-seeking feature in a spreadsheet is calculating a break-even quantity. 
Geographic Information Systems (GIS) - A support system that represents data using maps. It helps people access, display and analyze data that have geographic content and meaning. Check U.S. Geological Survey page on geographic information systems at http://www.usgs.gov/research/gis/ title.html. Examples of software packages include ArcView, Map/IDIS, Proximity, and TargetView.

Graphical User Interface (GUI) - A program interface that uses a computer's graphics capabilities to make the program easier to use. Graphical interfaces use a pointing device to select objects, including icons, menus, text boxes, etc. A GUI includes standard formats for representing text and graphics.

Group Decision Support Systems (GDSS) - An interactive, computer-based system that facilitates solution of unstructured problems by a set of decision makers working together as a group. It aids groups, especially groups of managers, in analyzing problem situations and in performing group decisionmaking tasks.

Groupware - Is software designed to support more than one person working on a shared task. Groupware is an evolving concept that is more than multiuser software which allows access to the same data. Groupware provides a mechanism that helps users coordinate and keep track of on-going projects. It allows people to work together through computersupported communication, collaboration, and coordination. Lotus Notes, Microsoft Exchange, Communicator, Novell GroupWise, Netscape SuiteSpot, Eclipse, Team Talk, and Internet Explorer/NetMeeting are examples of groupware products.

Heuristics - The informal, judgmental knowledge of an application area that constitutes the "rules of good judgment" in the field. Heuristics also encompass the knowledge of how to solve problems efficiently and effectively, how to plan steps in solving a complex problem, how to improve performance, and so forth. From the Greek word "Heuriskein" meaning "to discover."

Hypermedia - Combination of several types of media such as text, graphics, audio, and video.

Hypertext - An approach for handling text and other information that allows users to jump from a given topic, whenever he or she wishes, to related topics. A knowledge management technique in which knowledge is represented in linked documents and processed in a way that allows a user to select a highlighted marker on the currently viewed page and access a linked page about a topic indicated by the marker.
Icon - A visual, graphic representation of an object, word, or concept.

Independent Variables - Variables in a model that are controlled by the environment and that influence the results of a decision (also called Input Variables, parameters, givens).

Inference - The process of drawing a conclusion from given evidence. To reach a decision by reasoning.

Inference Engine - That part of an expert system that actually performs the reasoning function.

Information - Data that has been processed to add or create meaning and hopefully knowledge for the person who receives it. Information is the output of information systems.

Information Economics - This term refers to an approach to evaluating DSS/IS projects using a scoring approach to cost/benefit analysis that assesses technical and company tangible and intangible benefits and costs (see Parker and others, 1989).

Information Systems Architecture - A formal definition of the business processes and rules, systems structure, technical framework, and product technologies for business information systems. An information systems architecture consists of four layers: business process architecture, systems architecture, technical architecture, and product delivery architecture.

Interdependent Decisions - A series of decisions that are interrelated. A sequential set of decisions are usually interdependent.

Internet - The Internet (capitalized) refers specifically to the DARPA Internet and the TCP/IP protocols it uses. The Internet is a collection of packet-switching networks and routers that uses the TCP/IP protocol suit and functions as a single, cooperative virtual network. It is a global web connecting more than one million computers.

*Interoperability - The capability to communicate, execute programs, or transfer data among various functional units in a manner that requires the user to have little or no knowledge of the unique characteristics of those units (ISO TC211, specifically, ISO 19118 - Geographic information - Encoding). Or in more general terms, the ability to seamlessly and transparently "plug and play."

Intranet - An internal organizational network using TCP/IP with at least one web server that is only accessible by an organization's members or others who have specific authorization. A firewall and password protection limit access to the network. The intranet is used to share corporate information, including DSS capabilities. See web-based DSS at http://dss.resources.com/dss/online.html and check 
the Intranet FAQ at http://www.intrack.com/intranet/ ifaq.shtml.

Knowledge - Knowledge refers to what one knows and understands. Knowledge is sometimes categorized as either unstructured, structured, explicit or tacit. What we know we know is explicit knowledge. Knowledge that is unstructured and understood, but not clearly expressed is implicit knowledge. If the knowledge is organized and easy to share then it is called structured knowledge. To convert implicit knowledge into explicit knowledge, it must be extracted and formatted.

Knowledge Acquisition - The extraction and formulation of knowledge derived from various sources, especially from experts.

Knowledge Base - A collection of facts, rules, and procedures organized into schemas. The assembly of all the information and knowledge of a specific field of interest.

Knowledge Engineer - An AI specialist responsible for the technical side of developing an expert system. The knowledge engineer works closely with the domain expert to capture the expert's knowledge in a knowledge base.

Knowledge Engineering (KE) - The engineering discipline that involves integrating knowledge into computer systems in order to solve complex problems normally requiring a high level of human expertise.

Knowledge Management (KM) - KM is the distribution, access, and retrieval of unstructured information about "human experiences" between interdependent individuals or among members of a workgroup. Knowledge management involves identifying a group of people who have a need to share knowledge, developing technological support that enables knowledge sharing, and creating a process for transferring and disseminating knowledge.

Knowledge Management Software (KMS) - Software that can store and manage unstructured information in a variety of electronic formats. The software may assist in knowledge capture, categorization, deployment, inquiry, discovery, or communication. Products include electronic document management systems (EDMS). Visit KMWorld at http:// www.kmworld.com/.

Linear Programming - A mathematical model for optimal solution of resource allocation problems.

Metadata or Meta Data - Data about the data in a data warehouse. Metadata provides a directory to help the DSS locate the contents of the data warehouse; it is a guide to mapping data as it is transformed from the operational environment to the data warehouse environment; and it serves as a guide to the algorithms used for summarization of current detailed data. Metadata is semantic information associated with a given variable. Metadata must include business definitions of the data and clear, accurate descriptions of data types, potential values, original source system, data formats, and other characteristics. Metadata defines and describes business data. Examples of metadata include data element descriptions, data type descriptions, attribute/property descriptions, range/domain descriptions, and process/method descriptions. The repository environment encompasses all corporate metadata resources: database catalogs, data dictionaries, and navigation services. Metadata includes things like the name, length, valid values, and description of a data element. Metadata is stored in a data dictionary and repository. It insulates the data warehouse from changes in the schema of operational systems.

Methodology - A system of principles, practices, and procedures applied to a specific branch of knowledge.

Middleware - A communications layer that allows applications to interact across hardware and network environments.

Model Base - A collection of preprogrammed quantitative models (e.g., statistical, financial, optimization) organized as a single unit.

Model-driven DSS or Model-oriented DSS - This type of DSS emphasizes access to and manipulation of a model, e.g., statistical, financial, optimization and/or simulation. Simple statistical and analytical tools provide the most elementary level of functionality. Some OLAP systems that allow complex analysis of data may be classified as hybrid DSS systems providing both modeling and data retrieval and data summarization functionality. Data mining is also a hybrid approach to DSS. In general, model-driven DSS use complex financial, simulation, optimization and/or rule (expert) models to provide decision support. Model-driven DSS use data and parameters provided by decision makers to aid decision makers in analyzing a situation, but they are not usually data intensive, that is very large data bases are usually not needed for model-driven DSS. Early versions of model-driven DSS were called Computationally Oriented DSS by Bonczek and others (1981).

Modeling Tools - Software programs that help developers and users build mathematical models quickly. Spreadsheets and planning languages like IFPS are modeling tools.

Multidimensional Database (MDBS and MDBMS) A database that lets users analyze large amounts of data. An MDBS captures and presents data as arrays 
that can be arranged in multiple dimensions. Variables are the objects that hold data in a multidimensional database. These are simply arrays of values (usually numeric) that are "dimensioned" by the dimensions in a database. For example, a UNITS variable may be dimensioned by MONTH, PRODUCT, and REGION. This three-dimensional variable or array is often visualized as a cube of data. Multidimensional databases can have multiple variables, with common or a unique set of dimensions. This multidimensional view of data is especially powerful for OLAP applications.

Multiparticipant DSS - A decision support system that supports multiple participants engaged in a decisionmaking task (or functions as one of the participants). See Group DSS.

Multipoint Conference - An audio, data and/or video conference among more than two remote participants.

Multipoint Control Unit (MCU) - A device used to link remote sites into a single conference call or a device to manage several simultaneous, independent conferences.

Normalization - The process of reducing a complex data structure into its simplest, most stable structure. In general, the process entails the removal of redundant attributes, keys, and relationships from a conceptual data model.

Object - A person, place, thing, or concept that has characteristics of interest to an environment. In terms of an object-oriented system, an object is an entity that combines descriptions of data and behavior.

On-line Analytical Processing (OLAP) - Software for manipulating multidimensional data from a variety of sources that has been stored in a data warehouse. The software can create various views and representations of the data. OLAP software provides fast, consistent, interactive access to shared, multidimensional data. Check the Guide to OLAP Terminology from the OLAP Council at http://dss.cba.uni.edu/ glossary/olaptrms.html.

Operational or Transaction Database - The databaseof-record for a transaction-update system. The operational database is the source of data for the data warehouse. It contains detailed data used to run the day-to-day operations of the business. The data continually changes as updates are made and reflect the current value of the last transaction.

Optimize - The decision strategy of choosing the alternative that gives the best or optimal overall value.

Organizational DSS - A multiparticipant DSS designed to support a decision maker in a setting that has a more elaborate infrastructure than a group (i.e., involving specialized roles, restricted communication patterns, differing authority levels). See EnterpriseWide DSS.

Pivot - Changing the dimensional orientation of a display or report. See "rotate" in the OLAP Guide to terms at http://dss.cba.uni.edu/glossary/ olaptrms.html.

Planning - A managerial function concerned with making forecasts, formulating outlines of things to do, and identifying methods to accomplish them.

Prototyping - A strategy in system development in which a scaled down system or portion of a system is constructed in a short time, tested, and improved in several iterations. A prototype is an initial version of a system that is quickly developed to test the effectiveness of the overall design being used to solve a particular problem. Prototyping is similar to the Evolutionary (Iterative) Design Process. It is sometimes termed rapid prototyping and is similar to rapid application development (RAD).

Query - Generically, query means question. Usually it refers to a complex SQL SELECT statement for decision support. See Ad-Hoc Query.

Rapid Application Development (RAD) - Part of a methodology that specifies incremental development with constant feedback from the customers. The point is to keep projects focused on delivering value and to keep clear and open lines of communication. Oral and written communication is not completely adequate for specification of computer systems. RAD overcomes the limitations of language by minimizing the time between concept and implementation.

Rational Decision Behavior -Behavior that is goaloriented in reaching a decision. Behavior is guided by the consequences likely to result from the selection of a given alternative. A decision maker believes based upon analysis that a chosen alternative will result in achieving one or more desired objectives. Rational decision behavior should be supported by DSS.

Record - A group of data values consisting of one value for each of a prescribed set of relational fields; an occurrence of a record type.

Report and Query Tools - These tools produce a tabular list of information from data stored in a relational database. Examples include Microsoft Access and Brio Query.

Representation - The formulation or view of a problem. Developed so the problem will be easier to solve.

Result Variables - In a model-driven DSS a result variable shows the consequences of changing 
decision variables. Result variables are also referred to as dependent variables.

ROMC (Representation, Operations, Memory Aids, Mechanism Control) Design Approach - A

systematic approach for developing large-scale DSS, especially user interfaces. It is a user-oriented approach for stating system performance requirements (see Sprague and Carlson, 1982).

Rule - A formal way of specifying a recommendation, directive, or strategy, expressed as an IF premise THEN conclusion.

Scalability - The ability to scale hardware and software to support larger or smaller volumes of data and more or less users. The ability to increase or decrease size or capability in cost-effective increments with minimal impact on the unit cost of business and the procurement of additional services.

Semistructured Decisions - Decisions in which some aspects of the problem are structured and others are unstructured.

Sensitivity Analysis - Running a decision model several times with different inputs so a modeler can analyze the alternative results.

Shell - An expert system development tool consisting of two stand-alone pieces of software: a rule set manager and an inference engine capable of reasoning with rules set built with the rule set manager. A shell is a complete expert system stripped of its specific knowledge.

Simulation - A technique for conducting one or more experiments that test various outcomes resulting from a quantitative model of a system.

Specific DSS - A computer-based system that actually helps a person accomplish a specific task. "Specific DSS are the hardware/software that allow a specific decision maker or group of them to deal with specific sets of related problems" (see Sprague and Carlson, 1982:10).

Spreadsheet - In the accounting world a spreadsheet was and is a large sheet of paper that lays everything out for a businessperson. It spreads or shows all of the costs, income, taxes, etc., on a single sheet of paper for a manager to look at when making a decision. An electronic spreadsheet organizes information into columns and rows. The data can then be "added up" by a formula to give a total or sum. The spreadsheet summarizes information from many sources in one place and presents the information in a format to help a decision maker see the financial "big picture" for the company. A program that has a collection of cells whose values can be displayed on a computer screen. By changing cell definitions and having all cell values reevaluated, a user can readily observe the effects of those changes.
Decision support systems built using spreadsheet software are sometimes called Spreadsheet DSS. See "A Brief History of Spreadsheets" by Daniel Power at http://dss.cba.uni.edu/dss/sshistory.html.

Star Schema - A relational database schema organized around a central table (fact table) joined to a few smaller tables (dimension tables) using foreign key references. The fact table contains raw numeric items that represent relevant business facts (price, discount values, number of units sold, dollar value, etc.). The facts are typically additive and are accessed via dimensions. Since the fact tables are presummarized and aggregated along business dimensions, these tables tend to be very large. The basic premise of star schemas is that information can be classified into two groups: facts and dimensions. Facts are the core data element being analyzed. For example, units of individual items sold are facts, while dimensions are attributes about the facts. Dimensions are the product types purchased and the date of purchase. The star schema has also been called a star-join schema, data cube, data list, grid file, and multidimensional schema. The name star schema comes from the pattern formed by the entities and relationships when they are represented as an entity-relationship diagram (ERD). The results of a business activity are at the center of the star surrounded by the people, places, and things that come together to perform this activity. These dimensions are the points of the star.

Strategic Planning - A decision-making process in which decisions are made about establishing organizational purposes/missions, determining objectives, selecting strategies, and setting policies.

Structured Decisions - Standard or repetitive decision situations for which solution techniques are already available (also sometimes called routine or programmed decisions). The structural elements in the situation (e.g., alternatives, criteria, environmental conditions) are known, defined, and understood.

Symbolic Processing - Use of symbols, rather than numbers, combined with rules-of-thumb (or heuristics), in order to process information and solve problems.

Systems Development Life Cycle (SDLC) - A process by which systems analysts, software engineers, programmers, and end-users build systems. It is a project management tool, used to plan, execute, and control systems development projects. The steps in the cycle include: (1) determine user requirements; (2) systems analysis; (3) overall system design; (4) detailed system design; (5) programming; (6) testing; and (7) implementation. Each step is concluded by developing a written document that must be reviewed and approved before the next step begins. 
Ticker - A small Java Applet that displays a specific set of headlines, information, etc. Every web page that wants to display a Ticker must add some special HTML code into the page. This code ensures that the JAVA Applet is loaded from a server. Some parameters control the visible output like coloring and of course they control which news is loaded. Visit http:/ /7am.com/ticker/ or http://www.tickerland.com/.

Unstructured Decisions - This type of decision situation is complex, and no standard solutions exist for resolving the situation. Some or all of the structural elements of the decision situation are undefined, ill-defined, or unknown. For example, goals may be poorly defined, alternatives may be incomplete or noncomparable, and choice criteria may be hard to measure or difficult to link to goals.

User-friendly - An evaluative term for a decision support system's user interface. The phrase indicates that users judge the user interface as how easy to learn, understand, and use it is.

User Interface (or "Human-Computer Interface") The component of a computerized support system that allows bidirectional communication between the system and its user. This is also called the dialogue component of a DSS. An interface is a set of commands or menus through which a user communicates with a program.

Web-based DSS - A computerized system that delivers decision support information or decision support tools to a manager or business analyst using a "thinclient" web browser like Netscape Navigator or Internet Explorer. The computer server that is hosting the DSS application is linked to the user's computer by a network with the TCP/IP protocol. In many companies, a web-based DSS is synonymous with an enterprise-wide DSS that is supporting large groups of managers in a networked client-server environment with a specialized data warehouse as part of the DSS architecture.

"What If" Analysis - The capability of "asking" the software package what the effect will be of changing some of the input data or independent variables. 


\section{Appendix 1. Background Information}

By Thomas Gunther, Office of Water and Science, Department of the Interior

In 1997, an Interagency Group on Decision Support (IGDS) was formed to provide more communication and cooperation among developers of decision support system (DSS) tools and services aimed at land, natural resources, and environmental management. The mission of the IGDS is to encourage the use of and to advance the state of the art of these applications of DSS tools and systems. Its goals are to:

- Better achieve effective decision support capabilities for ecosystem management through collaboration.

- Establish a process for working toward a "nextgeneration" decision support capability.

- Develop, distribute, and regularly update understanding of existing decision support capabilities.

- Identify manager and stakeholder needs not currently met.

- Facilitate the integration of evolving scientific understanding into decision support.

- Identify emerging technologies and describe how they may contribute to decision support.

- Provide a forum for the interaction of users, designers, and contributors to the long-term development of decision support.

The charter of the IGDS (Lessard and Gunther, 1998) sets the goal of improving the management and protection of natural resources and the environment through development and application of decision support systems that facilitate the decision-making process and provide a suite of integrated tools and services. Two major objectives are to improve the interoperability, modularity, and transferability of decision support tools and services and to apply decision science principles to natural resource and environmental decision making.

In a series of meetings held in 1997 and early 1998, the IGDS-with participants from multiple agencies and the academic and private sectors-shared knowledge of existing decision support systems and applications and discussed unmet needs and opportunities. Our report supports their five conclusions (Lessard and Gunther, 1998):
- Powerful tools and systems are available or are under development.

- No one system provides or is likely to provide the broad range of capabilities needed by all decision makers and stakeholders.

- Some aspects of decision support are very sophisticated, while others are still in their infancy.

- No one agency or developer is likely to have the budgetary resources or mission to develop and maintain the full range of tools needed by decision makers.

- Evolving technology, inadequate budgets, and increasingly complex challenges of resource management combine to provide an opportunity for expanded cooperation in the development of the next generation of decision support.

The U.S. Geological Survey (USGS) formed a DSS Special Interest Group to pursue IGDS goals at the bureau level. In October 1998, the USGS Office of Biological Informatics and Outreach hosted a DSS workshop in Denver, Colorado (Getter and others, 1999). Although the USGS Biological Resources Division (BRD) has considerable DSS expertise and capabilities, no formal effort had been made to describe and document these activities and capabilities prior to this workshop.

The workshop brought together representatives of BRD science and technology programs to initiate an assessment of the division's capabilities and to define an appropriate role for BRD interaction and involvement with its partners. Action items developed from the workshop were to (1) develop a DSS framework document for use in biological research, (2) develop a "proof of concept" DSS based upon the framework document, and (3) more fully integrate DSS into BRD program elements. This report, "A Framework for Ecological Decision Support Systems: Building the Right Systems and Building the Systems Right," represents completion of the first objective identified at the workshop. Additional information concerning the DSS workshop can be found at the BRD DSS Web site (at http://biology.usgs.gov/dss/), which also houses 
responses to an interactive questionnaire initially posted to determine the USGS DSS inventory and user interests.

This report (1) presents a definition of a DSS that is consistent with that of the IGDS, (2) provides the characteristics and functionality of DSS, and (3) suggests generic steps for research and development of DSS. It stresses the importance of a team approach in developing a DSS, with early interaction among upper management, users, and system developers, and the development of user-friendly interfaces to ensure that the DSS will be effectively used for its intended purpose. By implementing the recommended procedures for verification and testing, users of a DSS can be assured that it performs its intended functions and measures up to required standards of quality and reliability. This biological framework for DSS development and use will help the biological community work together in achieving mutual goals. 


\title{
Appendix 2: Decision Support Capabilities for Future Technology Requirements
}

\section{Executive summary}

\author{
Edited by Gene Lessard, Senior Ecologist, National Watershed Coalition, Lessard@erols.com
}

In July 2000, a decision support system (DSS) workshop was held in Denver, Colorado, and jointly sponsored by the Interagency Group on Decision Support and the Aurora Partnership. Workshop discussion leaders provided the following synopses (printed verbatim from a workshop document) of their discussion groups to show the ongoing dialogue about future DSS technology requirements.

Figures had to be redrawn for printing purposes and are not the authors' original versions.

\section{Historical perspective}

The Interagency Group on Decision Support (IGDS) was formed in 1997 to discuss decision support tools, services, and other issues as they relate to natural resources and the environment. It has provided a forum for agency staff and stakeholders to meet and exchange information on currently available tools, address concepts and principles of decision science, and to explore the potential for greater cooperation and coordination among users and developers. The vision of the Group is to establish "a cooperative group of public and private stakeholders working together to build advanced systems for natural resource and environmental decision making." This vision led to the establishment of the Aurora Partnership.

The Aurora Partnership (AP) has a much greater reach than the IGDS. The Partnership is a collaboration of government and nongovernment, university, and private sector organizations. The approach of the Partnership is to engage in an open collaborative process to share ideas, information, and technologies to advance tools and systems that will enable the practical use of natural and social science in decision making. Their goal is to "stimulate the development and application of the next generation of information tools and systems for place-based management decision making through the collaboration of public and private stakeholders." Specific objectives are to:
- Improve the interoperability, modularity and transferability of decision support tools and services;

- Develop and apply decision science principles to place-based management decision- making; and

- Incorporate both the decision science principles and tools into a science-based decision support framework.

\section{Placed-based decision-making}

The process for making decisions for "places" will become increasingly complex and collaborative as land use intensifies, land values increase, more regulations are formulated, and government authorities and nongovernment stakeholder groups multiply. Multiple authorities (such as drainage and watershed authorities, county boards, state and federal regulators, regional air quality managers) will need to negotiate with each other and engage stakeholders in these negotiations before they select a course of action (or inaction).

There will be increasing demands for technology to help scope the issues, enhance communications in multiple media, identify and present relevant data, manage and refine processes, picture future options and outcomes, and channel participants towards endpoints and decisions. New technological capabilities will 
emerge from academic research, industry investments and government experiments. The question posed by the Aurora Partnership is simply this - can a conscious effort by an affiliation of academics, industry and government help us more rapidly and effectively shape and realize the potential advantages of these technologies?

Assuming the answer to this question is yes, how can we help quicken improvements in placed-based decisions through collaborative technology initiatives, and what are the critical steps? The first step is to envision and communicate how we want technology to aid in our future decision processes. This requires a strong dialogue between the developers/pioneers of different technology innovations, and placed-based decision- makers. The better we can describe desirable end states in decision processes, the better we will be able to shape technologies to help us achieve these end states. Conferences, publications, talks and web site demonstrations can all help elicit descriptions of these future decision capabilities and nurture a strong and interacting community of technology developers and pioneer users.

\section{The workshop}

This workshop is one of a series of workshops aimed at addressing the goals and objectives of the IGDS and the Aurora Partnership (For more information see "Strategic Plan" www.aurorapartnership.com) and beginning the envisioning and communicating process. The organizing committee for this workshop includes Tom Gunther (USDI), Bill Goran (DoD), Tom Hart (DoD), Ken Snyder (DoE), Gary Fisher (USDI), and Maury Nyquist (USDI).

Decision support systems have been defined in many ways, reflecting different emphasis or points of view. For the purposes of this workshop we define Placebased Decision Support Systems (PBDSS) as combinations of computer hardware, software, data and models that allow users to better understand complex issues, develop alternative approaches to resolving those issues, and test them within a "what if" environment. Geographic information systems (GIS) are clearly a crucial element of such systems, but need to be augmented by additional decision support tools.

The combination of new capabilities and growing demand are generating greater expectations for decision support, and identifying new challenges for developers and users alike. This workshop is intended to discuss challenges and opportunities to meet these expectations and to outline the next steps in a strategy for the next stage of PBDSS development. In discussions, meetings and workshops over the last several years, the IGDS and the Aurora Partnership have identified several topical areas that we addressed in this workshop:

- Decision processes;

- Collaborative tools for decision support;

- Information management and interoperability;

- Knowledge management and decision support; and,

- Computation, communication, and data storage.

Issues are explored within the context of a decisionmaking processes currently being used (Tom Gunther, this report). Tom notes that decision-making is the result of a sequence of implicit or explicit steps. He describes a generalized process for decision-making, which outlines the steps: process mapping, problem framing, intelligence gathering, evaluating and choosing alternatives, and learning from the outcome of the decision. This decision process is often a function of the type of decision to be made. For instance, decisions made under the National Environmental Policy Act have legal, well-documented, procedures to follow. Other routine decisions may involve only a portion of the process. And, lastly, collaboration is often an essential ingredient in decision-making. In summary, Tom notes that these three aspects-the process, the type of decision, and the need for collaborationencompass the environment in which decision support systems and tools will be used.

Tom sees a future in which decision-makers have "a toolbox containing a variety of tools to help address the range of place-based problems. Some tools would assist in understanding and improving the process itself; others would assist specific stages, such as intelligence gathering or evaluating alternatives; and others would help identify very specific tools for specific problems or parts of problems (e.g. hydrologic models). New tools could be added as new problems arise or as conditions change, without the need to extensively modify or replace either the toolbox or existing tools. The interface would be consistent, and learning about the capabilities of the toolbox and the geographic area being considered would be cumulative. The toolbox would be one of many offered by different vendors, and all would be capable of incorporating tools from other sources."

With collaboration a major part of the environment of decision-making, it seems reasonable to develop tools specifically to enhance the collaborative process. Mike Case (this report) notes that "collaborative tools can help in two important ways. First, they can serve as tools to apply proven group decision support methods and processes. Second, they can serve as an aid in 
helping group members arrive at a shared understanding of technical information relevant to their issues." In addition, collaborative tools can allow stakeholders to work at their own time (asynchronous) and place (distributed) versus the traditional "town meeting" venue (synchronous and collocated). Mike notes that "effective collaborative tools should help stakeholders in a decision process to arrive at better decisions when measured against metrics of consensus, awareness, representation, time, and/or cost."

To arrive at a vision for the future of collaborative tools, Mike first examines some of the impediments to effective collaboration such as organizational competition, identification of stakeholders, the knowledge and skill of individual stakeholders, and others. With these impediments in mind, collaborative tools can accomplish three goals: to develop shared purpose, to develop shared understanding, and to provide a focus for resources.

Any decision-making process requires data that can be converted into information and, ultimately, into knowledge. This conversion process needs to be managed in a transparent manner to the user. Jeff Holland (this report) notes that "information management involves the purposeful, directed manipulation of data as it moves from information (e.g., inputs for decision-making) to knowledge (e.g., belief and value sets used as overarching constraints, goals, and objectives in decision-making)." And, "interoperability is defined as the capability of productively and seamlessly moving from data to information to knowledge, and back, in a manner whose infrastructure is transparent."

Jeff's vision for the future focuses around the "seamless movement of data, information, and management from research to analysis to synthesis to adaptation. This is particularly true... where new science findings must flow to implementation, and where feedback produces the need for adaptation of a given management decision." With this in mind, Jeff describes five areas of functionality for interoperable information systems:

- Access: Differing stakeholders utilize different components of an interoperable information system from their geographically distributed desktops.

- Catalog: Provide for a repository for techniques/ algorithms in a standard, web-searchable paradigm.

- Smart agent/knowledge management: Methods to capture the knowledge base, sharing "lessons learned," "decision model," "case studies," etc. for repositing in the cataloging framework above.

- Motivation: Develop mechanisms that strongly encourage the development of in-house and marketplace interoperable solutions.

- Processing: Interoperability and reuse of tools through standards.

Knowledge is an asset that needs to be managed. However, knowledge management presents many additional dilemmas. Wayne Schmidt (this report) identifies knowledge management as "an integrated, systematic approach to identifying, managing, and sharing an enterprise's information assets, including documents, databases, policies, procedures, and implicit expertise. The purpose of this integration is to make available the validated 'Decision Support Process' that will guide the user to the decision point. Fundamentally, knowledge management makes the collective information and experience of an enterprise available to the individual knowledge worker, who is responsible for using it wisely and for replenishing the knowledge asset. This ongoing cycle promotes a learning organization, stimulates collaboration and empowers people to continually enhance the way they perform work."

Wayne's vision of the future for knowledge management includes a "searchable distributed library of Decision Support Processes" (DSPs) with each DSP being a "complete 'case study' of the process, data requirements, analytic tools..."

The identification of a decision process, the need for and use of collaboration (Tom Gunther), development of collaborative tools (Mike Case), managing data, information (Jeff Holland), and Knowledge (Wayne Schmidt) all seem straight forward. In fact, it can be argued that organizations are already doing all of the above. However, as Doug Johnston (this report) notes "the information environment remains disorganized with relevant data distributed across many databases and systems with differing descriptions based on disciplinary focus. Models for analysis or creation of data are similarly distributed and disciplinary. Thus decision makers, confronted with a problem to solve, must seek out relevant data, acquire that data, transform it to a common framework, identify the models that will address the problem being solved, acquire the computational resources required to run the models, and finally, if all goes well, actually begin to address the real problem they set out to solve."

Doug notes that the objective of applying technology to decision-making is to "make available resources (computational, data, models) at the right time to the right problem." The problem with technology application is more institutional in nature than technical. Organizations choose not to adopt standards, use protocols, or provide access to information. Doug presents the concept of a "broker" which represents a "tiered set of services built to connect the technologies in ways that can bring existing capabilities to bear fruit 
quickly." A broker filters through available options and presents a limited set of comparable options. The foundation of the broker concept is the catalog. The catalog contains available elements or products and a method for querying. An abstraction defines attributes, a definition translator matches abstract definitions to actual elements, and a store provides a set of pointers to the actual resources.

\section{Next steps in the strategy}

A number of themes were emphasized by each of the work groups. The first of these was the need for demonstration programs focused only in part on addressing a specific local issue. A clear additional goal of these demonstration programs would be to leave a legacy of capability within the community that will be applied to future issues.

Place-based issues are seldom one time one decision in nature - rather, the issues need to be continuously addressed and the public and stakeholders frequently informed. One important goal of a program to develop and demonstrate improved place-based decision-making is to grow sustainable capabilities for localities and regions. To help encourage this capacity building, demonstration and test-bed programs should use one metric for success relating to the "sustainable capability creation." This capacity building has several dimensions-have stakeholders learned to work better together? Is there local available expertise in the technologies needed to support improved place-based decisions? Is there a process in place to obtain relevant data-especially dynamic data elements? Is there an improved climate in the community/region for decisionmaking?

Demonstrations can be conducted within existing federal, state or privately sponsored programs, or could be a context for fashioning new programs. Metrics for success would not just be related to the successful use of some new capability in a decision process, but the successful transition of this capability into the local community, and the contribution of lessons learned about this capability back to a network of developers and other potential placed-based users. Metadata about applications and lessons learned would be contributed towards web accessible repositories to help inform increase the body of available expertise and experts.

Specific recommendations for demonstration programs from the workshop are:

- Develop a set of case studies and/or other "lessons learned," including evaluations of tools and applications, meta-analyses and retrospectives on past place-based activities.

- Initiate a series of linked demonstration projects, each of which will be designed to improve the support for the decision process.

- Develop and conduct a series of highly-focused technology that, by design, investigate the better of several means for achieving interoperable information technologies. Envisioned is a set of five to seven demonstrations, chosen to reflect differing natural and water resources decision processes, each with differing stakeholder requirements, that exercises the differing interoperability and information aspects listed above. It is recommended that the Federal government agencies with major roles in the natural and water resources area come together to establish these demonstrations in direct concert with stakeholder groups and industry.

- Develop a case study. Build a set of DSPs for a particular problem domain.

- Integrate a lessons learned capability and a way for users to evaluate the DSPs.

- Focus on the establishment of a national center or centers that will coordinate a small number of testbed programs while providing collaborative implementation toolkits to groups that are interested in experimenting with place-based decision support. An alliance of federal and state agencies, standards organizations, vendors, and consultants should pool resources on a voluntary basis to:

- Encourage local centers for Place-based Decision Support;

- Act as a repository and resource for "best practice" process templates;

- Act as a repository and resource for lessons learned;

- Provide free or low cost visualization, modeling, and scenario generation tools; and,

- Fund a small number of pilot demonstration programs.

Creation of repositories and catalogue services is another important step in facilitating local decision making. Such services are needed to ensure that relevant data, expertise, software and process information all gets to the right persons at the right time in the right format. Creation of networks of services that are "registered" against local applications will help connect relevant experts, data and expertise with local community and regional efforts. Applications of decision technology both draw from and contribute towards these repositories and catalogue services-and the network of services grows in terms of both the availability of data and the processing of relevant information with each application conducted. 
Specific recommendations for creation of repositories and catalogue services from the workshop are:

- Develop open "wizards" that facilitate placing data within web-accessible repositories. Define these repositories using standards as well so that they can be queried and mined by different users who see them as virtual repositories.

- Develop a consistent, integrated problem solving computational environment, a "decisioning" world on the web, is needed. Major Federal government organizations and industry should collaborate to provide the critical mass needed to properly develop the environment.

- Develop a standard set of agents, acting behind the scenes over a network or the web, to facilitate data/ information creation, location, and retrieval, model/tool selection, visualization, etc.

- Develop a search and presentation scheme for users.

- Develop a web site to improve user access.

Another important step is to develop and implement standards for interoperability of capabilities-so that new functions easily fit into an extensible framework, and all capabilities from any vendor or data store can be used together. The Open GIS Consortium is dedicated to this end state, and various other standards groups are focusing on components of this goal. Such efforts are part of the critical path for future decision-making, because of the need to share and access data and tools and expertise relevant to any local issue and the need to share across localities and regions.

Specific recommendations for standards for interoperability from the workshop are:

- Develop and utilize one set of national interoperability standards.

- Provide financial incentives through contracts to promote the use of established standards.

- Eliminate designed non-interoperability ("not invented here")- promote the use of standards through Agency order at the national or agency level.

- Make new technology implementations transparent to the user-this would be done primarily through the use of object-oriented, modular developments and the use of standards/agents as listed above.

Besides implementing standards, agencies need to develop a framework approach into which all of their data, models and commercial capabilities are mapped. These frameworks are needed to get disparate technology pieces (technical systems, business systems, commercial software, data bases) into a self-improving, scalable and evolving and web-based context. This "framework" needs to eliminate requirements for duplicating data entry across systems; automatically gathers data on users, applications, processes and usage context; create templates and process flows to reduce steps and avoid costs for future efforts; and draw upon agency wide stores of data and tools to seek experts and experience relevant to any specific task. Agency frameworks can drive the "interoperability" context for industry products, and can be mimicked at regional and local levels.

Specific recommendations for developing a framework approach from the workshop are:

- Develop and inventory tools that can help assess decision processes (rather than decisions).

- Develop a set of guides (probably through a World Wide Web site) to the process and the currently available tools and systems. Identify specific tools for different stages of the decision process.

- Establish a new set of smart agents or wizards to monitor and feedback the actual processes used in decision making for a given situation.

- Provide a higher conceptual or natural language query capability to facilitate decision support to many stakeholders-develop the means for decision-makers to query data of all types (including modeling and simulation data) using terms (language) they understand and identify with.

- Define a model for a Decision Support Process (DSP). This would include attributes and methods for combining DSPs and updating them as tools change.

- Address the issue of getting new DSPs. Perhaps there could be contractual language that would require contractors to input their process and results in an electronic form in addition to the normal printed documents.

- Inventory computerized tools that are currently available and which, with some modification, can aid in decision-making.

- Initiate a "Request for Information" for PBDSS tools and systems, and begin a multi-agency evaluation and analysis of these tools and systems.

\section{Who has what role?}

There are roles for government organizations (at multiple tiers), educational institutions, industry, and non-government organizations aimed at shaping improved future placed-based decision making. However, the roles for any one task are not necessarily distinct. For instance, research can be performed by government, academics, and private firms alike. In 
general, the roles for the various players are outlined below:

- Communicate a Vision

- Communities and Regions - Help to shape vision

- Federal Agencies and Organizations - Participate in shaping vision/running workshops

- Consortia and Standards Organizations - Build standards responsive to vision/ approach

- Academics - Conduct research and education towards future decision technologies and processes

- Private Firms - Affirm vision with responsive products and services

- Demonstrations

- Communities and Regions - Conduct demos on local issues

- Federal Agencies and Organizations - Provide resources for demo programs

- Consortia and Standards Organizations - Operate test-beds

- Academics - Participate/assist in demos

- Private Firms - Provide resource assistance

- Repositories and Templates

- Communities and Regions - Draw from and contribute to repositories

- Federal Agencies and Organizations - Build repositories for objects, lessons learned, processes

- Consortia and Standards Organizations - Help nurture standard approaches for repositories

- Academics - Develop concepts and prototypes

- Private Firms - Develop capabilities that utilize repositories
- Interoperative Products

- Communities and Regions - Use/require interoperable products

- Federal Agencies and Organizations - Use/ require interoperable products and develop scopes of work

- Consortia and Standards Organizations - Focus standards efforts on inter-operability

- Academics - Develop concepts and participate in test-beds

- Private Firms - Form consortia and provide testbed involvement to make interoperable tools

- Build Local Capacity/Experts

- Communities and Regions - Build sustaining capability through demos

- Federal Agencies and Organizations - Encourage capability building through demo programs

- Consortia and Standards Organizations - Use test-beds to help build/sustain capacity

- Academics - Collaborate with local/regional entities to build/sustain capabilities

- Private Firms - Focus grants and assistance towards capability building

- Building Frameworks

- Communities and Regions - Focus market demands towards highest needs

- Federal Agencies and Organizations - Create overarching information technology concepts and approaches for "seamless" capabilities

- Consortia and Standards Organizations Develop standards that facilitate frameworks

- Academics - Develop concepts and prototypes

- Private Firms - Build tools and services that fit into, expand and are compatible across frameworks 


\title{
Appendix 2: Continued
}

\section{Decision Processes}

\author{
By Thomas Gunther, Office of Water and Science, U.S. Department of the Interior, Washington, DC 20420
}

\section{Introduction}

Decision-making is the result of a sequence of implicit or explicit steps, represented, in one fashion, in figure 1. It begins with the recognition of a problem or an opportunity, or just a vague awareness that some condition or thing could be improved. In this representation, process mapping, problem framing, intelligence gathering, evaluating and choosing alternatives, and learning from the outcome follows recognition (While there are many other ways to represent the decision process, they are, for the purposes of this paper, interchangeable). Of course, the activity or experience at any one stage- - say intelligence gathering-can alter the outcome of an earlier stage-in this case, perhaps problem framing. Indeed iteration through such "feedback loops" is essential to "good" decision making, allowing new information, knowledge and ideas to be incorporated, and permitting adaptive management. "Good" decisions are, at least in part, a function of the amount of time and effort expended on the process and at each of the stages.

The process of making decisions also varies with the type of decision and the number of decision-makers. Some decisions, such as those covered by the National Environmental Policy Act, must follow procedures established by law and be well documented. Some are dependent on data delivered by real time sensors or experiments, and thus require rapid integration of data and models to meet management needs. Others are routine management decisions regarding operations or maintenance. And some decisions, usually affecting longer-term plans, require the collaboration of a range of stakeholders, often with conflicting goals and objectives.

These three aspects of decision-making-the process, the type of decision, and the amount of collaboration necessary - constitute the environment in which decision support tools and systems will be used. The same set of tools may provide support for different types and stages of decision-making, but be applied in different ways, with different intensity, and with different requirements for precision and presentation.

\section{State-of-the-art in decision processes}

Decision support tools and systems cannot supplant the decision making process. However, there are an increasing number of computerized tools that can provide assistance, and they are becoming increasingly sophisticated. There are tools to help brainstorm, discover and measure preferences and performance, poll participants, facilitate and manage meetings, and provide a formal record of the process. There are other tools to assist in understanding and displaying the impacts of proposals, including the trade-off among various criteria with different alternatives, changes in the way an area will appear, and other often nonquantifiable changes in the quality of life. But many of these tools come from different specialties, disciplines, or developers, and they each tend to focus on a relatively narrow issue. They are developed and used independently of each other, and moving data, stakeholder input, models and results from one to another is difficult or impossible. Even if a community is aware of the range of tools that can assist them in making decisions, the tasks of assembling, learning, and applying them puts these capabilities beyond the reach of most places.

\section{Vision for the future}

A manager, group, or community would have a toolbox containing a variety of tools to help address the range of place-based problems. Some tools would assist in understanding and improving the process itself; others would assist specific stages, such as intelligence gathering or evaluating alternatives; and others would help identify very specific tools for specific problems or parts of problems (e.g., hydrologic models). New tools could be added as new problems arise or as conditions change, without the need to extensively modify or replace either the toolbox or existing tools. The interface would be consistent, and learning about the 


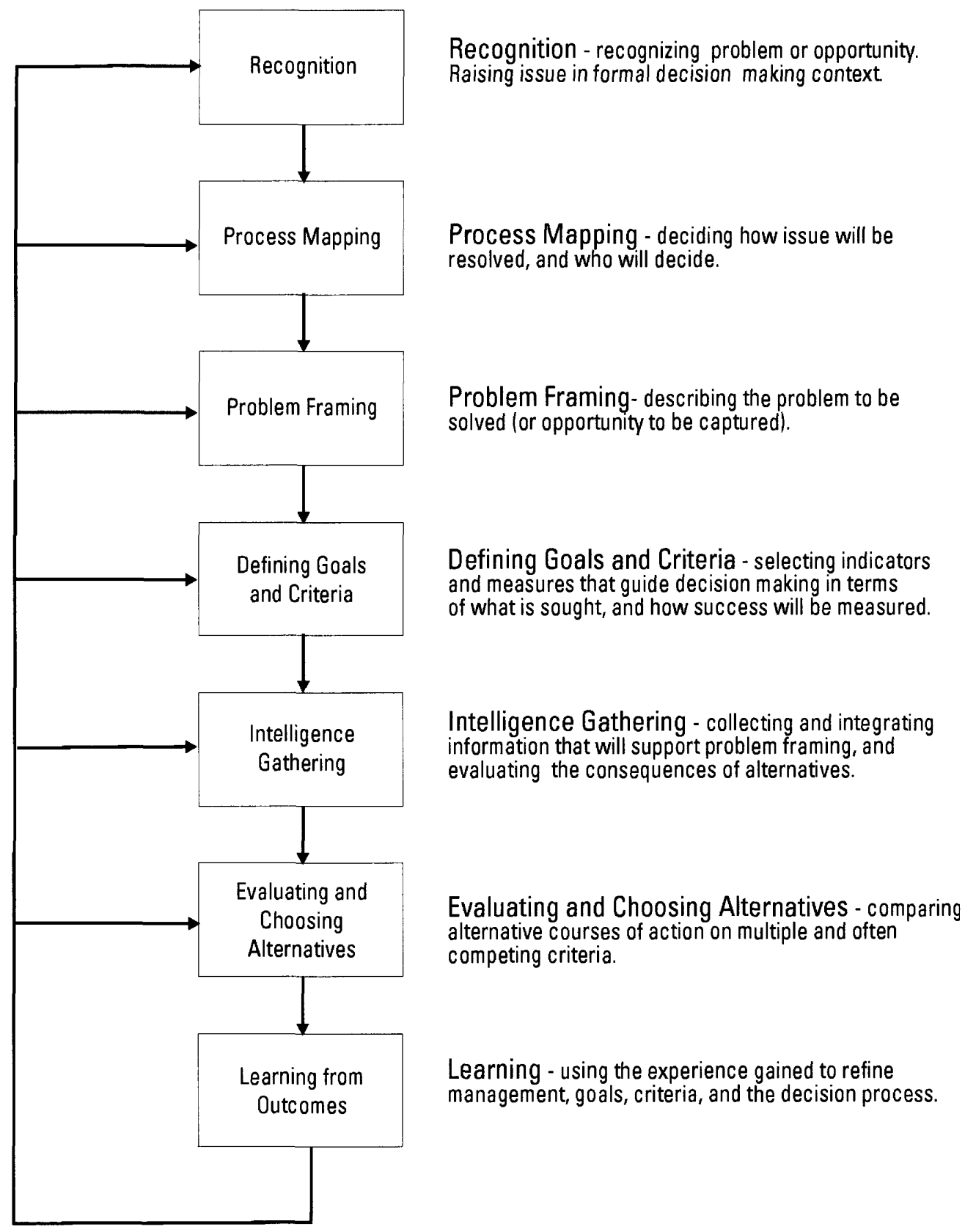

Figure 1. Representation of the decision process (adapted from Dave Cleaves in "Report on the Decision Support Systems Workshop," USGS, May, 1999.)

capabilities of the toolbox and the geographic area being considered would be cumulative. The toolbox would be one of many offered by different vendors, and all would be capable of incorporating tools from other sources.

\section{Strategies for implementation}

Several specific steps that should be taken to improve support for the decision making process are given 
below. They are intended to increase user awareness of existing tools (whether or not they are designed for place-based management), and move toward the concept of integrated toolboxes.

- Develop and inventory tools that can help assess decision processes (rather than decisions). In most cases, these tools will be in the form of paper guidelines. Is the range of stakeholder goals and values identified and reflected? Have criteria for selecting among alternatives been established and are performance measures selected?

- Inventory computerized tools that are currently available and which, with some modification, can aid in decision making. Examples include "groupware," tools to elicit preferences and weights, project management software, and visualization programs. These tools were typically developed for different applications (such as software development), but have many capabilities important to place-based management.

- Initiate a "Request for Information" for PBDSS tools and systems, and begin a multi-agency evaluation and analysis of these tools and systems.

- Develop a set of guides (probably through a World Wide Web site) to the process and the currently available tools and systems. Identify specific tools for different stages of the decision process.

- Develop a set of case studies and/or other "lessons learned," including evaluations of tools and applications, meta-analyses and retrospectives on past place-based activities.

- Initiate a series of linked demonstration projects, each of which will be designed to improve the support for the decision process. 


\title{
Appendix 2: Continued
}

\section{Collaborative Tools for Decision Support}

\author{
By Mike Case, U.S. Army Engineer Research and Development Center, Champaign, Illinois 61826-9005
}

\section{Introduction}

In today's public and private decision environments, many choices formerly made by individuals are being made by groups of people. In addressing the question of how collaborative tools might help these groups, it is important to recognize that effective collaboration is primarily a social process that requires an understanding of human behavior. In the "place-based" decision arena, collaboration tools can help in two important ways. First, they can serve as tools to apply proven group decision support methods and processes. Second, they can serve as an aid in helping group members to arrive at a shared understanding of technical information relevant to their issues.

Effective collaborative tools should help stakeholders in a decision process to arrive at better decisions when measured against metrics of consensus, awareness, representation, time, and/or cost. Collaborative tools may help groups to develop shared understanding of issues, evaluate alternative solutions, build consensus, or resolve disputes. Tools may also be used to break down barriers of time and space in communication between stakeholders. In addition to the traditional "town meeting" venue (synchronous and collocated), tools allow collaborators to work at their own time (asynchronous) and own place (distributed). Although it is generally recognized that the bandwidth of human communication is greatest in face-to-face meetings of stakeholders, the asynchronous and distributed capabilities offered by automated collaborative tools can act to augment limited resources of time and funding.

\section{State-of-the-art in collaborative tools and decision support}

The current status of collaboration tools encompasses both traditional and electronic media. Place-based decision support requires proactive efforts to meet with stakeholders and solicit involvement. Techniques such as focus groups, breakout groups, flip charts, and "place-the-dot" style voting are commonly used techniques. Despite their low level of technology, they may still be considered state-of-the art.

Electronic media has enhanced rather than replaced many of the manual methods mentioned above. Tools such as e-mail, mailing lists, chat rooms, web servers, and discussion forums are all examples of on-line technologies that ease the process of distributing information and exchanging points of view. Online meeting tools such as Netmeeting and C-U See Me offer new ways to overcome barriers of time and distance through video teleconferencing and application sharing.

The class of tools commonly called Group Decision Support Systems (GDSS) provides utilities to improve elicitation of viewpoints, generation of ideas, discussion, and consensus building. Typically, such systems are set up in a dedicated room in which each participant has their own screen and keyboard. Meetings may be facilitated or not and input may or may not be anonymous.

A final class of collaboration tools gives collaborating groups an online location to keep shared documents and data. These tools offer electronic document management functions, communication utilities for members (forums, chat, etc.), and shared visualization of graphics (CAD, GIS, images). These tools are readily available over the Internet and accessible through web browsers or client software. Discipline specific varieties of these tools add features needed to perform tasks unique to a discipline. For instance, software configuration control tools offer utilities for version control and defect management.

\section{Vision for the future}

If the goal is to improve the effectiveness of placebased collaboration, how can collaboration tools help? To answer this question, let's examine some impediments to effective collaboration and suggest some 
strategies to overcome them. Having done that, we will suggest some ways in which tools can help.

1. Competition. People and organizations (stakeholders) have valid reasons to compete for funds, space, resources, recognition, or other goals. Collaboration is impeded by a lack of common goals. Win-win strategies are desirable, but not always possible.

2. Turf. Stakeholders seek control over decisions that affect them. A real or perceived loss of control may impede collaboration.

3. Stovepipes. Organizational boundaries of responsibility, accountability and authority may prevent collaboration.

4. Efficiency. Developing consensus among all involved stakeholders can be difficult and lengthy process. Sometimes it appears easier to work alone or in small groups. This can be an unfortunate strategy when stakeholders that were not considered put up road blocks (see \#5).

5. Identification of Stakeholders. Sometimes it is very difficult to recognize who the stakeholders are in an issue. Late involvement of stakeholders sets back the collaboration process.

6. Purpose. Members of a group may not always have a shared understanding to the desired outcome of collaboration.

7. Process. Lack of buy-in to process and tools can inhibit collaboration.

8. Knowledge and Skill. Stakeholders may bring very different backgrounds, skills, and understanding to a problem. Some may not understand important social or technical issues.

9. Resistance to Change. Some stakeholders may be more comfortable with maintaining the status quo.

10. Resource limits. Collaboration requires an investment of resources (i.e., time, personnel, energy, and funds).

Given these typical impediments to collaboration, how can automated tools provide assistance? In the desired future, strategies and tools will be available to develop shared purpose, to develop shared understanding, and to provide resources. Each of these three goals is addressed below.

- Shared Purpose. Although stakeholders may have conflicting goals, it is important that these goals be articulated and expressed. Only then can a group work towards achieving an acceptable solution. Resources will be available that will help groups to achieve a preferred future focus. Rather than concentrating on overcoming problems, proven decision support strategies are available that can help groups to develop and realize a shared vision.
Group Decision Support (GDSS) Systems, Computer Supported Collaborative Work (CSCW) Tools, and lessons-learned systems can assist in overcoming impediments $1,2,3,4,5,6$, and 7 .

- Shared Understanding. Work in the social sciences shows that groups must work through a process of developing a shared understanding of issues. This is especially critical when technical issues or jargon are involved. Tools that can help illustrate the meaning of highly technical analyses to people of disparate education and backgrounds will help groups to achieve shared understanding more quickly. For example, visualization and simulation using GIS, 3D and 4D (time if the fourth dimension) are very effective in communicating complex ideas and consequences. Impediments 6,7 , and 8 are affected.

- Provide Resources. Traveling to meetings, arranging schedules, or retrieving obscure information all require time, money, and personal motivation. Web-based tools that improve access to materials, information, other stakeholders, will lower resource-driven barriers. Home, civic, or regionally-oriented information resources can make it easier for local citizenry to research issues on their own time and schedule. One suggestion is to set up resource centers in libraries or local schools. Readily available electronic meeting rooms will provide virtual locations for people to meet. Public access sites to these virtual resources will help increase usage. Impediments 5, 8, and 10 are affected.

\section{Strategies for implementation}

It is apparent that many tools are already available that will help achieve the desired future. The recommended strategy is to focus on the establishment of a national center or centers that will coordinate a small number of test bed programs while providing collaborative implementation toolkits to groups that are interested in experimenting with place-based decision support. An alliance of federal and state agencies, standards organizations, vendors, and consultants should pool resources on a voluntary basis to:

- Encourage local centers for Place-based Decision Support;

- Act as a repository and resource for "best practice" process templates;

- Act as a repository and resource for lessons learned; 
- Provide free or low cost visualization, modeling, and scenario generation tools; and,

- Fund a small number of pilot demonstration programs.
Resources from this alliance would be available on the condition that the organization or individual using the resources provide lessons learned or add to the knowledge base of process templates. 


\title{
Appendix 2: Continued
}

\section{Information Management and Interoperability}

\author{
By Jeff Holland, U.S. Army Engineer Research and Development Center, Vicksburg, MS 39180-6100
}

\section{Introduction}

Information management involves the purposeful, directed manipulation of data as it moves from information (e.g., inputs for decision making) to knowledge (e.g., belief and value sets used as overarching constraints, goals, and objectives in decision making). Data are formatted, evaluated, and distilled in the process of becoming information as shown in the schematic (Figure 2) below. Information is evaluated, integrated, and applied in the process of becoming knowledge.

Interoperability ("I*" in Figure 2) is the capability of productively and seamlessly moving from data to information to knowledge, and back, in a manner whose infrastructure is transparent.

\section{State-of-the-art in information management and interoperability}

The current state of practice for information management and interoperability is provided in bullet format below.

- Developing Standards Poorly Used. There are several groups developing (or have developed) standards that will strongly facilitate interoperable information management. These groups include:

- OGC-Open GIS Consortium

\begin{tabular}{|c|c|c|c|}
\hline & $\begin{array}{c}\text { Science } \\
\text { Community }\end{array}$ & & User \\
\hline Data & $\begin{array}{c}\underset{\text { formatted }}{\stackrel{l^{*}}{\longrightarrow}} \\
\text { evaluated } \\
\text { results } \\
\text { distillation }\end{array}$ & Information & $\begin{array}{l}\underset{\text { interpreted }}{\longrightarrow} \stackrel{\left.\right|^{*}}{\longrightarrow} \text { Knowledge } \\
\text { integrated } \\
\text { evaluated }\end{array}$ \\
\hline
\end{tabular}

Figure 2. Conceptual view of information management and interoperability.
- ISO-International Standards Organization

- FGDC-Federal Geodetic Data Committee

- Industry-through the organizations above and through marketplace activities related to commercial product development

Clearly, there are a number of existing and oncoming efforts at developing standards. However, the use of these standards is highly non-standard between, and within, major organizations.

- No Money to Apply Standards. Organizations do not yet appear to be resourcing the use of standards in their activities to an adequate level. This seems particularly true of efforts to reformulate existing software and databases within new standards contexts.

Middle-ware development. Significant strides have been made in the development of middle-ware to support interoperable information management.

- Proprietary Solutions. There are a number of inhouse proprietary methods for achieving interoperability within a given organization or element that do not translate across the information spectrum.

- Emergence/Development of Cross Cutting Formats. There are several data/information formats that are emerging (e.g., XML, GML, JAVA, etc.) that offer significant promise in supporting interoperability. However, these technologies have not been fully implemented.

Understanding the role of each of these items requires one to have a broader grasp of the current state of users of data, information, and knowledge. This state is presented below.

- Generators vs. Users. There is a significant difference in the expectations of, and capability for, information management between generators of information (e.g., scientific and engineering community) and the users of information (e.g., decision makers, the public, etc.). This involves all facets of information flow as shown in Figure 2.

- Internet has Raised the Level of Expectations. Users from all levels of sophistication now believe that data, information, and knowledge should be 
available at their finger tips through the WorldWide Web. This raises the level of expectation regarding the productive use of the Internet in reaching information.

- Institutional Barriers. Institutions often have a "not-invented-here" philosophy that acts as an impediment to the use of standards that affects interoperability.

- Lack of Reward. There are limited financial incentives for industry to develop interoperable marketplace solutions. Further, there is a perception within government organizations that interoperability is a luxury rather than a requirement for sound management.

- Lack of Standards Across the Board. There are still major technological areas that have not as yet promulgated data/information standards.

- Output Definition. As a follow on to the Generator vs. Users bullet above, there are requirements for the output of data/information in highly different ways to meet the specific needs of a given group of stakeholders. This involves multiple issues of information management and interoperability so users can obtain the output type(s) of choice.

The bottom line is that there is a lack of interoperability as one goes back and forth through the data-information-knowledge spectrum shown in Figure 2.

\section{Vision for the future}

The desired future is one of fully, across-the-board interoperable information management services available to the broadest range of stakeholders possible. The desired information environment is shown in Figure 3. The desired future involves seamless movement of data, information, and management from research to analysis to synthesis to adaptation. This is

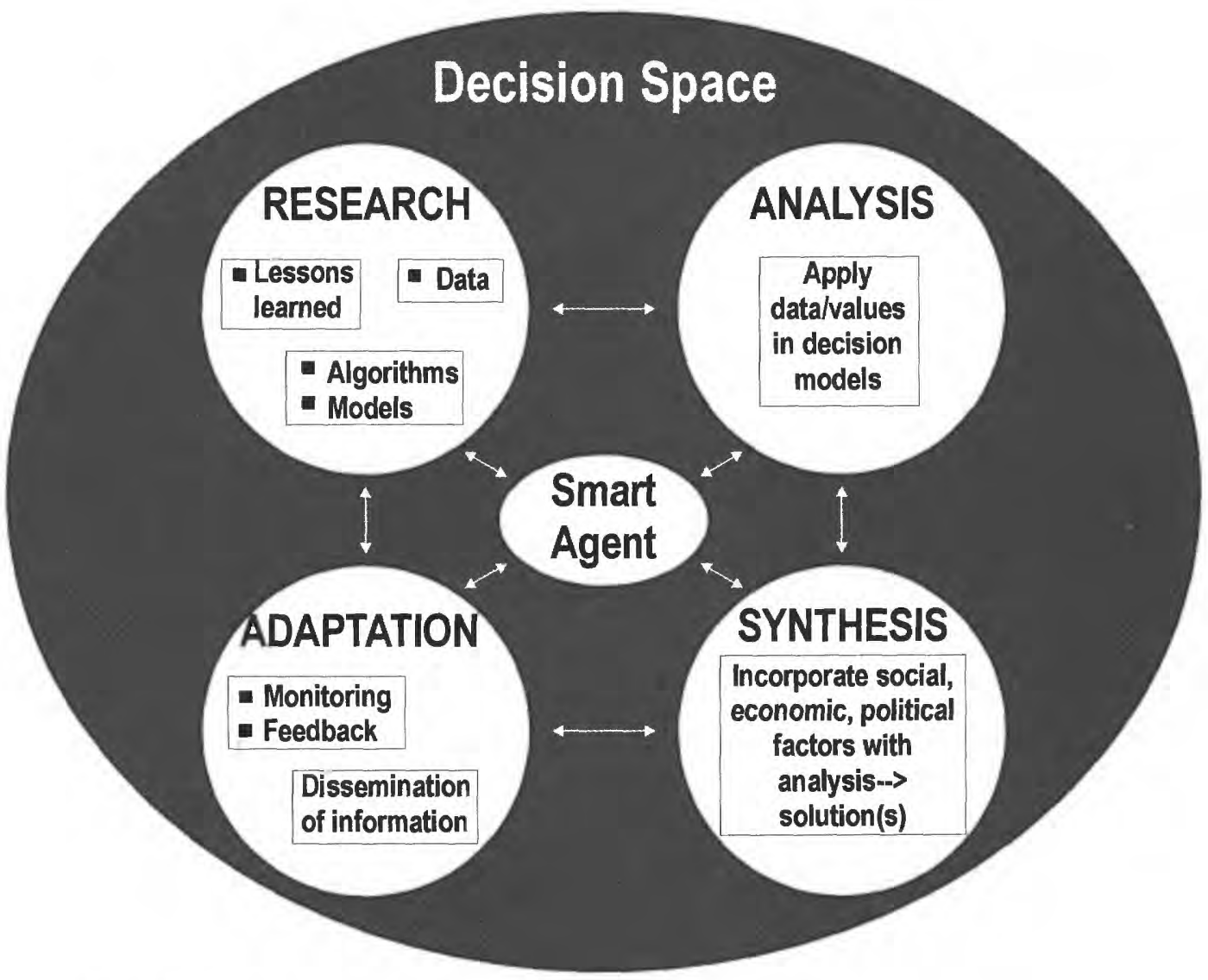

Figure 3. Desired future state of information management interoperability. 
particularly true in the decision science area where new science findings must flow to implementation, and where feedback produces the need for adaptation of a given management decision.

Toward this end, there are five areas that are viewed as desired levels of functionality for future interoperable information systems. These are:

1. Access: Differing stakeholders utilize different components of an interoperable information system from their geograhically-distributed desktops.

2. Catalog: Provide for a repository for techniques/ algorithms in a standard, web-searchable paradigm.

3. Smart agent/knowledge management: Methods to capture the knowledge base, sharing "lessons learned," "decision model," "case studies," etc. for repositing in the cataloging framework above.

4. Motivation: Develop mechanisms that strongly encourage the development of in-house and marketplace interoperable solutions.

5. Processing: Interoperability and reuse of tools through standards.

The desired future would have the following goals/ objectives/features.

- All data would have standardized repository by data type;

- Users would obtain and manage data via integrated problem solving environments;

- Interoperability and reuse of tools promoted through standard use of standards;

- Smart agents facilitate input requirement, tool selection \& results analysis;

- Computational environment facilitates sharing "lessons learned," "algorithm," "decision model," "case studies";

- Repository/tracking of decision process facilitated through problem solving environment;

- One set of national interoperability standards utilized;

- Financial incentives for contractors/vendors to use standards set in place;

- Eliminate designed non-interoperability ("not invented here");

- Provide a higher conceptual or natural language query capability to facilitate decision support to many stakeholders; and,

- Make new technology implementations transparent to the user.

This set of goals/objectives/features would apply across the spectrum listed in Figure 3. This alone would promote interoperability in a meaningful way.

\section{Strategies for implementation}

The desired future is achievable through strategic implementation activities as listed below. It is noted that this list is incomplete both in scope and in specifics. However, it is clear that the proposed implementation strategy includes marketplace, organizational, technical, and programmatic factors, any of which can frustrate convergence to the desired future state. The implementation concepts are keyed to the desired future state bullets listed above.

- All data would have standardized repository by data type-develop open "wizards" that facilitate placing data within web-accessible repositories. Define these repositories using standards as well so that they can be queried and mined by different users who see them as virtual repositories.

- Users would obtain and manage data via integrated problem solving environment-a consistent, integrated problem solving computational environment, a "decisioning" world on the web, is needed. Major Federal government organizations and industry should collaborate to provide the critical mass needed to properly develop the environment. Note that this is not to suggest the development of a single environment with one look and feel, but a global environment with a user-customizable toolkit that builds off a common set of information technologies and standards.

- Interoperability and reuse of tools promoted through standard use of standards-this goal can be realized through the use standards, development of repositories, development of the problem solving environment listed above, and through several of the items listed below.

- Smart agents facilitate input requirement, tool selection and results analysis-develop a standard set of agents, acting behind the scenes over a network or the web, to facilitate data/information creation, location, and retrieval, model/tool selection, visualization, etc. These agents would be "freeware" to insure their broad-based use.

- Computational environment facilitates sharing "lessons learned," "algorithm," "decision model," "case studies" - this would be an extension of the user environment above to some extent, but would also employ smart agents and the creation of publication standards to mine and reposit new findings and information into repositories in object formats.

- Repository/tracking of decision process facilitated through problem solving environment-a new set 
of smart agents or wizards should be established to monitor and feedback the actual processes used in decision making for a given situation.

- One set of national interoperability standards utilized - this should be an established, focused, directed, and funded objective of the major federal agencies, with incentives to industry, to insure that one national set of standards is created. The referenced incentives are needed to insure that these standards become the marketplace standards as well to insure life-cycle use and implementation.

- Financial incentives for contractors/vendors to use standards-major procurement organizations (e.g., government) should provide financial incentives through contracts to promote (require?) the use of established standards. Other marketplace incentives, such as the use of cooperative agreements combining government and private funding to develop standards, should be employed.

- Eliminate designed non-interoperability ("not invented here")- promote the use of standards through Agency order at the national or agency level.

- Provide a higher conceptual or natural language query capability to facilitate decision support to many stakeholders-develop the means for decision makers to query data of all types (including modeling and simulation data) using terms (language) they understand and identify with.

- Make new technology implementations transparent to the user-this would be done primarily through the use of object-oriented, modular developments and the use of standards/agents as listed above.

In addition to the points raised above, it is essential that a paradigm be established that encourages the differing stakeholders within the decision process to conduct the activities at which they excel rather than all the components of the process per se. For example, the development of an interoperable information technology architecture envisioned might cause one to conclude that decision makers with limited technical background could simply go to the web, access data, execute models, and perform visualization at will. This should not be either the expectation or the goal. Rather, the interoperable model presented above should be used to facilitate the interactions between experimentalists, modelers, integrators, analysts, managers, and the public rather than replace said interactions. Toward this end, it is essential that the process of creating the envisioned interoperable environment also include checks and balances that facilitates the science and engineering community's verification of tools/models/ methods prior to their use by decision makers-and that stakeholders have the opportunity to directly frame the use of said tools in deciding alternative futures for a given site.

\section{Recommendations}

It is tempting to recommend simply that the items listed above that are required to achieve the desired future be funded and conducted as presented. However, there is significant investigation and discovery left to conduct to understand the best ways to implement the goals/ objectives listed above.

Toward that end, it is recommended that a series of highly-focused technology demonstrations be created and conducted that, by design, investigate the better of several means for achieving interoperable information technologies. Envisioned is a set of five to seven demonstrations, chosen to reflect differing natural and water resources decision processes, each with differing stakeholder requirements, that exercises the differing interoperability and information aspects listed above. It is recommended that the Federal government agencies with major roles in the natural and water resources area come together to establish these demonstrations in direct concert with stakeholder groups and industry. The time period for the demonstrations should be no more than two years. 


\title{
Appendix 2: Continued
}

\section{Knowledge Management and Decision Support}

\author{
By Wayne Schmidt, U.S. Army Engineer Research and Development Center, Construction Engineering Research \\ Laboratory, Champaign, IL 61826-9005
}

\section{Introduction}

"If I have only a hammer, the world looks like a nail." As the number and complexity of environmental analysis tools grows and the decision process become more complex, it becomes increasing difficult to keep current on the best methods. This paper envisions how the emerging field of knowledge management can be used to assist in the applications of analytical tools, data representation and modeling to help the user solve problems related to natural resources and the environment. This paper describes the current state of the art for knowledge management, a vision of how knowledge can be managed to support natural resource and environmental decision making, and a strategy for demonstrating the vision.

\section{Why is knowledge management important?}

The term Knowledge Management (KM) has become a key issue for government, industry and certainly Information Technology (IT) executives. Organizations are becoming increasingly aware of the importance of managing knowledge, like any other asset, to improve their competitive advantage. Careful application of knowledge, like other assets, can result in better decisions, particularly, at the working level. Typically, there is a wide variety of analytical tools available. The users dilemma often becomes one of managing the entire decision support process. Restated, "What is the sequence of tasks that will reliably produce the report/ documentation to support the conclusions reached."

\section{What is knowledge?}

Before one can talk about knowledge management, it is useful to have an understanding of how knowledge differs from information or data. Peter Drucker defines knowledge as "Information that changes something or somebody - either by becoming grounds for actions or by making an individual (or an institution) capable of different or more effective action."

Knowledge is the result of aggregating process, information, analysis, and supporting documentation into a package that will support a conclusion. It is the end result of combining these factors and our experience. The concept of transforming data into information is well known and understood. This concept can be extended to characterize knowledge as part of a relationship pyramid (Figure 4). The pyramid illustrates how:

- Data in context yields information;

- Information after analytical effort yields understanding;

- Understanding when combined with professional judgment yields knowledge; and,

- Knowledge in turn supports decision-making.

There are a wide variety of analytical tools available. The tools assist the user in moving from information to understanding. Information/data is processed and displayed in a variety of forms and analyzed by various

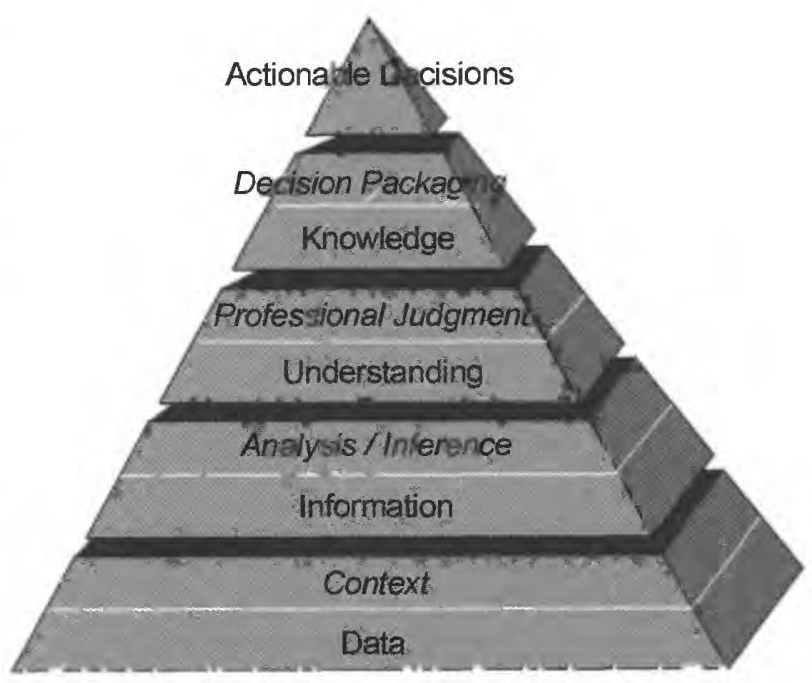

Figure 4. Relationship pyramid. 
models to present data in a way that can be easily understood. While this is an important part of the entire decision making process, there are many other tasks that must be accomplished. For example, there is data to be gathered, presentations to be made, reports to be made, decision papers, executive summaries, public announcements etc. All of these tasks are part of the knowledge that must be managed to aid the user in completing the decision process.

\section{What is knowledge management?}

Knowledge Management is an integrated, systematic approach to identifying, managing and sharing an enterprise's information assets, including documents, databases, policies, procedures, and implicit expertise. The purpose of this integration is to make available the validated "Decision Support Process" that will guide the user to the decision point. In many organizations this Decision Support Process is well understood for a particular class of problems. However, when new problems arise, or institutional knowledge is lost due to retirement, transfer, etc., effectiveness suffers while the process is relearned.

The level of technical ability of stakeholders within the decision process is often very different. The citizen will have the least technical ability to understand and manipulate the data. The decision maker has a better understanding, the engineering staff has still more and finally the research modelers have the best understanding of the data. However, the researcher is removed from the decision process and is often solely concerned with analysis. The users in the shaded area are the intended users of a knowledge management capability. They understand the nature of the decision, but don't have the knowledge to plan and manage the Decision Support Process. In short, they need a knowledge management capability (Figure 5).

\section{State-of-the-art in knowledge management}

Knowledge management, while the subject of many conferences, books, papers and tools, is immature. There are tools that accomplish some knowledge management but do not address the entire concept.

Traditionally, libraries provide the knowledge management function. Libraries store the accumulated knowledge of the ages. The time-honored way, especially in the scientific community, is to make knowledge explicit by publishing. However, most of the

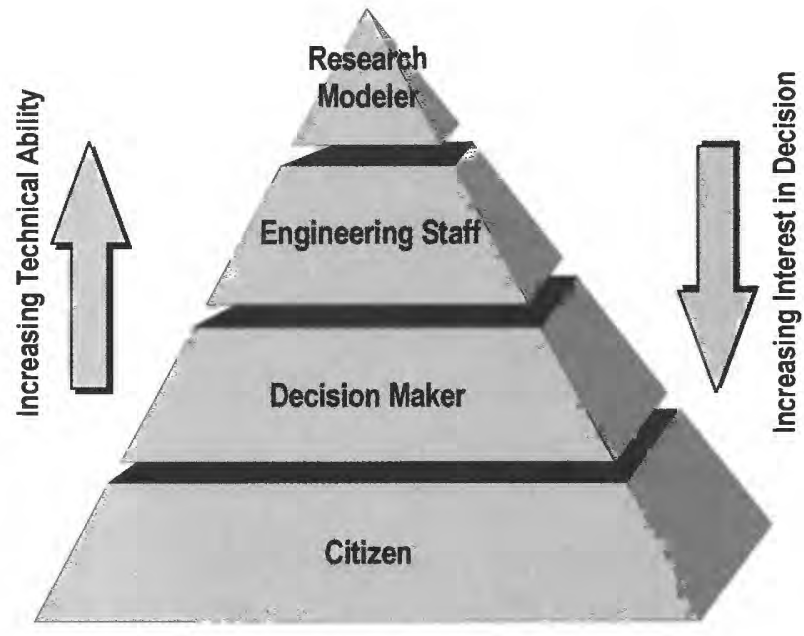

Figure 5. Pyramid of technical ability of stakeholders.

scientific literature is very technical and only useful to other scientists, not the problem solvers. It also deals with theory and not the tasks that are required to complete the decision process. In addition, it is paper based and difficult to reuse.

The publishing process is long and resource intensive. It is seldom used in the business world and notably not used to make the business process explicit. Some businesses publish "Standard Operative Procedures" and "Policies." Keeping these printed documents current is a resource intensive problem. Thus, they become obsolete and fail to be effective sources of knowledge. Again, they are usually paper-based.

Many tools are available to deal with parts of the knowledge management problem. These tools are often called knowledge management solutions but only address part of the problem. For example, there are very complex search engines that will search the web, your stored documents, email and even databases. But they don't address why you want this information, where it fits within the decision support process and where an approved method of reaching a conclusion exists.

The technologies for Knowledge Management revolve around implementing the KM Process. Each of the stages has existing technologies, although many are marketed under the global "knowledge management" title. Some technologies span several of the stages; but addressing the entire spectrum requires careful thought and planning. The existing technologies include:

- Process Development:

- IDEF models (approved Federal Government Std)

- Rummler-Brache 
- Search:

- Search engines (Infoseek, web crawler)

- Information portals (Yahoo, Altavista, DogPile)

- Databases (e.g., Lexis-Nexis)

- Information Systems (GIS)

- Data mining and warehousing

- Expertise tracking and locating

- Organize:

- Decision Support Systems

- Word processors

- Knowledge Mapping

- Workflow

- Create:

- Group Decision Support Systems

- Collaboration Portals

- Discussion groups

- Video Teleconferencing

- Storytelling

- Capture:

- Peer review

- Cataloging and indexing

- Business practice repository

- Documents designed for retrieval by coding content (XML)

\section{Vision for the future}

Any vision for knowledge management must be focused on a user community. Our knowledge management vision is from the perspective of the user community described earlier. Thus, the vision is: A searchable distributed library of Decision Support Processes (DSP). Each DSP is a complete "case study" of the process, data requirements, analytical tools, and report examples necessary to propose and support decision alternatives.
A DSP is a linked set of tasks that describe how to achieve a solution (Figure 6). Some of the tasks will require manual action, e.g., "coordinate with the EPA." Others will require the use of word processors, e.g., "Develop a status statement for the public affairs office." Still others will suggest specific tools to accomplish data analysis.

Each DSP has these attributes:

- Decision/problem addressed

- Description

- Where used and when

- Developer of the DSP

- Relevant policies

- Tools used

- Start conditions

- Data needed (minimum)

- Products produced

- References

The DSP library is searchable by these attributes. Thus, the user can search for all uses of a particular tool. For an expert user, the selection of analytical tools may be critical. Selection of a tool will then drive a reformulation of the DSP.

\section{Strategy for implementation}

- Define a model for a DSP. This would include attributes and methods for combining DSPs and updating them as tools change.

- Develop a case study. Build a set of DSPs for a particular problem domain.

- Develop a search and presentation scheme for users.

- Integrate a lessons learned capability and a way for users to evaluate the DSPs.

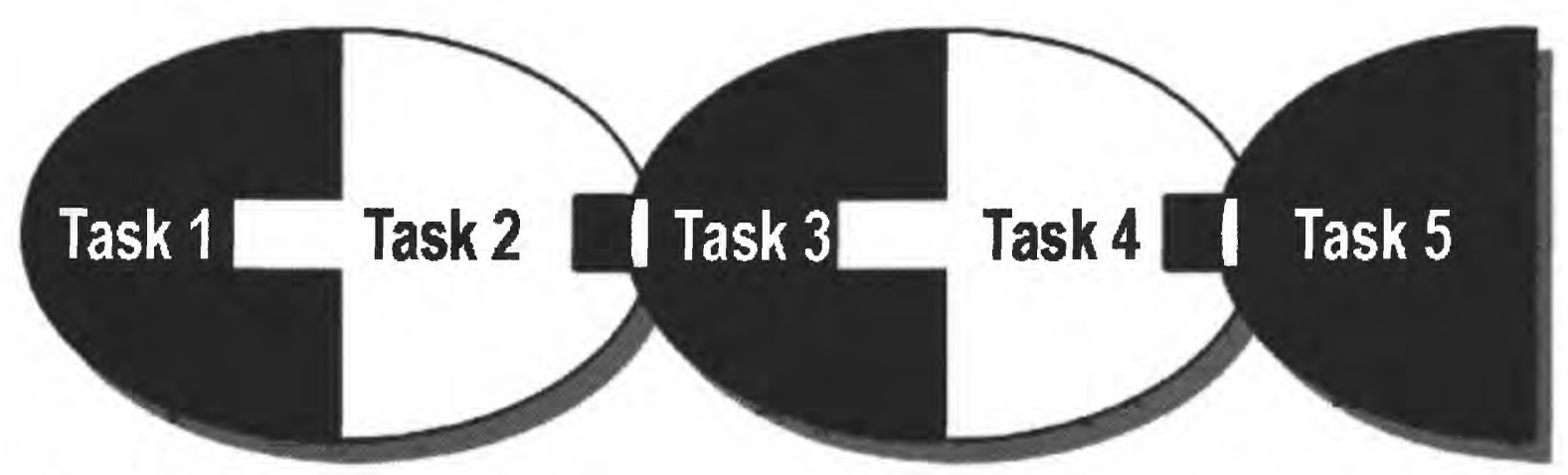

Figure 6. Decision support process. 
- Develop a web site to improve user access.

- Address the issue of getting new DSPs. Perhaps there could be contractual language that would require contractors to input their process and results in an electronic form in addition to the normal printed documents.

\section{In summary}

Fundamentally, knowledge management makes the collective information and experience of an enterprise available to the individual knowledge worker, who is responsible for using it wisely and for replenishing the knowledge asset. This ongoing cycle promotes a learning organization, stimulates collaboration and empowers people to continually enhance the way they perform work. 


\title{
Appendix 2: Continued
}

\section{Computation, Communication and Data Storage}

\author{
By Doug Johnston, Senior Research Scientist, National Center for Supercomputing Applications, University of \\ Illinois at Urbana-Champaign
}

\section{Introduction}

\section{What is issue/objective?}

The rapid development of higher and higher performance computing and communications seems to continue unabated. Power that exceeds supercomputers of ten to fifteen years ago, costing millions of dollars are now available on the desktop for less than $\$ 2,000$. Network communications used by a small number of academic and government researchers is now accessible to virtually all people through browser and Internet technologies. While there is little doubt that increasing scalable networking and computation power is being developed, there is also a concern that there is a deficiency in comparable development in language, tools, and interface environment to make this power usable to a broader (i.e. non-scientist) community. Usable power refers to making access to the computational resources easier, by reducing or removing the considerable barriers that remain.

The barriers to more effective use in the decision making environment remain numerous. The information environment remains disorganized with relevant data distributed across many databases and systems with differing descriptions based on disciplinary focus. Models for analysis or creation of data are similarly distributed and disciplinary. Thus decision makers, confronted with a problem to solve, must seek out relevant data, acquire that data, transform it to a common framework, identify the models that will address the problem being solved, acquire the computational resources required to run the models, and finally, if all goes well, actually begin to address the real problem they set out to solve.

The objective of technology applied to decision making then, is to make available resources (computational, data, model) at the right time applied to the right problem. The focus of this discussion is on methods for making resources available to the user.

\section{Status}

In many respects, the technological advances in the last few decades, and in the last few years, have greatly enabled access to information resources. The rapid growth of distribution of information over the Internet and access through Web browsers is certainly an indication of that. At the same time however, it has enforced the realization that physical access to information through networking is not the same as usable access. The proliferation of information on the World Wide Web has shown how unorganized and undocumented the information world truly is. Focusing only on geographic information resources, finding data for the location of interest, at the necessary scale, using an appropriate attribute domain, is itself a major challenge. The growth of clearinghouses and data catalogues is a step toward overcoming some of these barriers, and research efforts in digital library technologies promise advances as well.

In decision making, data are only part of the equation. To assess the impact of events or predict the outcomes of alternative plans and policies, models are required to represent the processes or phenomena of interest. Models, built by scientists, can be extremely rich but can also be extremely opaque to a potential user who has the expertise to use the information generated by the models, but possibly not the disciplinary focus of the modeler. Arguably, many science models are built by scientists for scientists.

The world is also seeing a tremendous growth in the amount of data available. This is partly because more data are being stored in accessible (i.e., digital) forms, but also because more data are being collected. The launch of the new generation of remote sensing platforms promise wide coverage at very high resolution, but the price of that is the tremendous growth in the volume of data that needs to be stored and analyzed. 
While the raw volume of storage capacities of magnetic drives and off-line storage continues, the issue of searching and rapidly accessing that information remains.

The development of common interface protocols developed through the PC "revolution" and more recently web browser technology for the Internet "revolution," has increased the provision of uniform access to resources by a larger audience (whose principle business is not the computational technology). Communications protocols such as TCP/IP have enabled higher levels of development built on top of these foundational technologies.

There is no question that there are good computers, good models and good data available, but in many cases they are developed for single purposes by and for single disciplines. The fundamental issue in many cases is not a technical one, but an institutional one of choosing to adopt standards, use protocols, provide access, etc. Nonetheless, technological advances in the infrastructure development can facilitate use of these formidable resources. The question is, how do we make models/ data accessible to a broader user community?

\section{Needs/requirements}

The problems of access to computational and information resources suggest that integration or logical connection between resources is a desired focus area. The following needs/requirements are proposed as areas of high priority.

DATA

- Cohesive data sets linked independently of individual projects.

- Data extraction and discovery tools

- Uniform means to access large data sets

DATA/MODELS/INTERFACE

- Integrated Search capabilities

- Integration of storage media

- Primary (on line)

- Secondary (disk backup)

- Tertiary (tape storage)

MODELS

- Model definition language

- Data input output specification

- Model documentation for suitability for use

INTERFACE

- Uniform/consistent understanding of available resources and access

- Push technologies (to notify of changes, etc).

- Paradigms and tools to deal with large, hierarchical datasets, studies, knowledge.

\section{State of the art computation, communication and data storage}

\section{Large storage}

There exist many approaches to management and storage of large datasets, including, on the hardware side, Giga- and Terabyte primary, secondary, and tertiary storage systems, and on the software side, several high-performance commercial systems such as Oracle, Informix, MSQL, etc. The principle issue in this arena is defining a mechanism for robust and efficient access to these systems. Network bandwidth available to the user, physical access to storage devices by users, overhead costs with maintaining large, complex datasets, data input output bottlenecks from storage to processor are a few of the issues that need to be addressed to keep up with the advances in online and archival storage.

These issues of course, are not unique to Federal Agency Decision Support so there are many efforts throughout the CS community to address these including efforts such as the Hierarchical Data Format (HDF) (www.hdf.ncsa.uiuc.edu) developed for NASA,

\section{Simulation models for science}

Many, many models exist for various purposes. Even models for the same purpose employ different theoretical concepts of physical or social processes, different numerical algorithms for solving applications of the theoretical concepts, and certainly different programming languages, file types, data sources, etc. to execute the models. There is no question that there are good models and tools for a wide range of application, and better ones (higher resolution, capturing finer and finer details of the phenomena, greater efficiency, etc) but the issue remains from a users or market perspective of being to choose among them, or being able to assemble components in order to construct a system for addressing a particular class of problem that may span processes. At a foundational level, there are many technologies being employed to facilitate the construction of complex, scientific models including the Modular Modeling System, DIAS, etc., to name a very few.

\section{Web Browsers}

It is easy to forget the birth of widespread use of the internet, but the general public and all the e-commerce and other industries spawned from it, started in the 
1980 's with the world wide web consortium and in 1993 with the release of Mosaic, the first multifunction web browser. The development of web browsers, email, on-line transactions, exchange of multi-media documents (and the tools to use them) and other technologies has enabled tremendous growth in the range of services available through the net (and the expectations associated with it). At the same time, the proliferation of search engines, agents and other tools to find information show how difficult it currently is to find just the right piece of information. While highly structured information classification systems may limit the richness of information query, unstructured classification systems cannot guarantee access to information, even if it exists within the system.

The bottleneck to improved use of information and computation is argued here to be less an issue of needing greater advances in technological development (although technological development is critical) but more an issue of finding ways to increase the rate of adoption of existing and emerging technology by decision makers. The current state is illustrated in Figure 7. Components of the decision making environment are shown as corners of the pyramid. They are identified as the data base, the model base, the computation base, and the user base. The volume of the pyramid represents the structure that links these components together. The solid gray corners are representative of the current state of development. In other words, we argue that the individual sectors (data

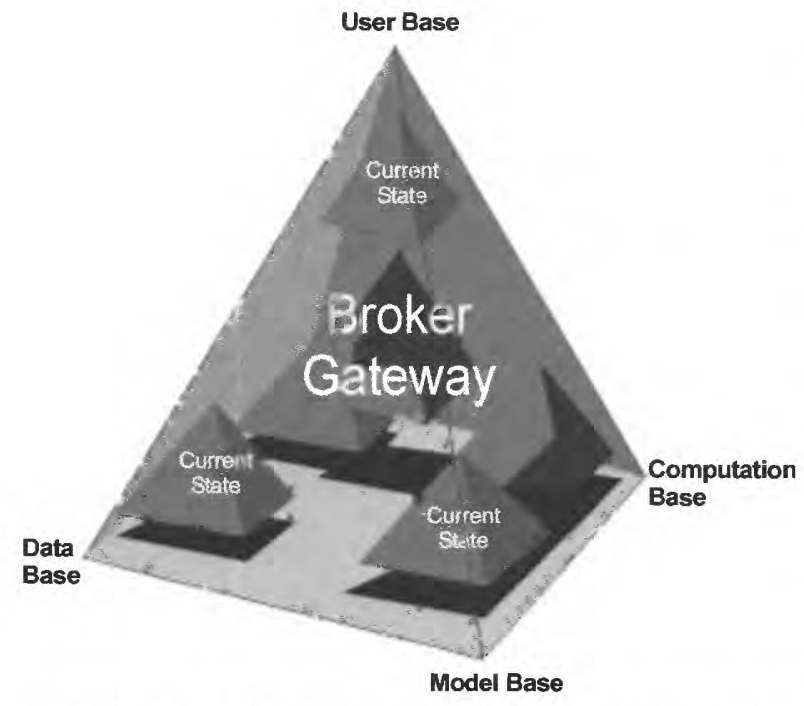

Figure 7. State of decision-making technology environment. base technologies, modeling tools, computational resources, and user interfaces) have each seen development, but the filling the pyramid, and the full integration of the resources remains incomplete.

\section{Vision for the future}

There are two (NOT mutually exclusive) strategies for completing the structure. One strategy is to continue building from the corners, by developing faster computers, larger databases, better models, and better user interfaces. Another strategy is to create a new node in the center and build outward to join the foundational technologies where they currently exist, and co-develop along with these technologies. This node is termed a broker and represents a tiered set of services built to connect the technologies in ways that can bring existing capabilities to bear fruit quickly.

\section{Broker}

The broker functionality is borrowed from the familiar services sector. A broker provides a means of filtering through available options and presenting a more limited set of comparable options for subsequent action. The architecture for this broker service (Figure 8) consists of a set of components providing the information needed to filter through the information. It should be noted that some of the barriers presented above exist here, but the emphasis here is on confronting those barriers directly by providing a tiered approach to implementation.

\section{Catalogs}

The foundational element of the broker function is the construction of catalogues providing information on the available elements (products). The catalog contains the attributes of the elements and a method for querying these attributes.

\section{Abstraction}

The definition of attributes of catalog elements requires the creation of model, data, and computation abstractions, that is, generalizable descriptions of relevant features that form the structure of the query and can be populated by the producers of the elements. The abstraction is independent of specific implementations (programming languages, units of analysis, dates of record, etc.). 

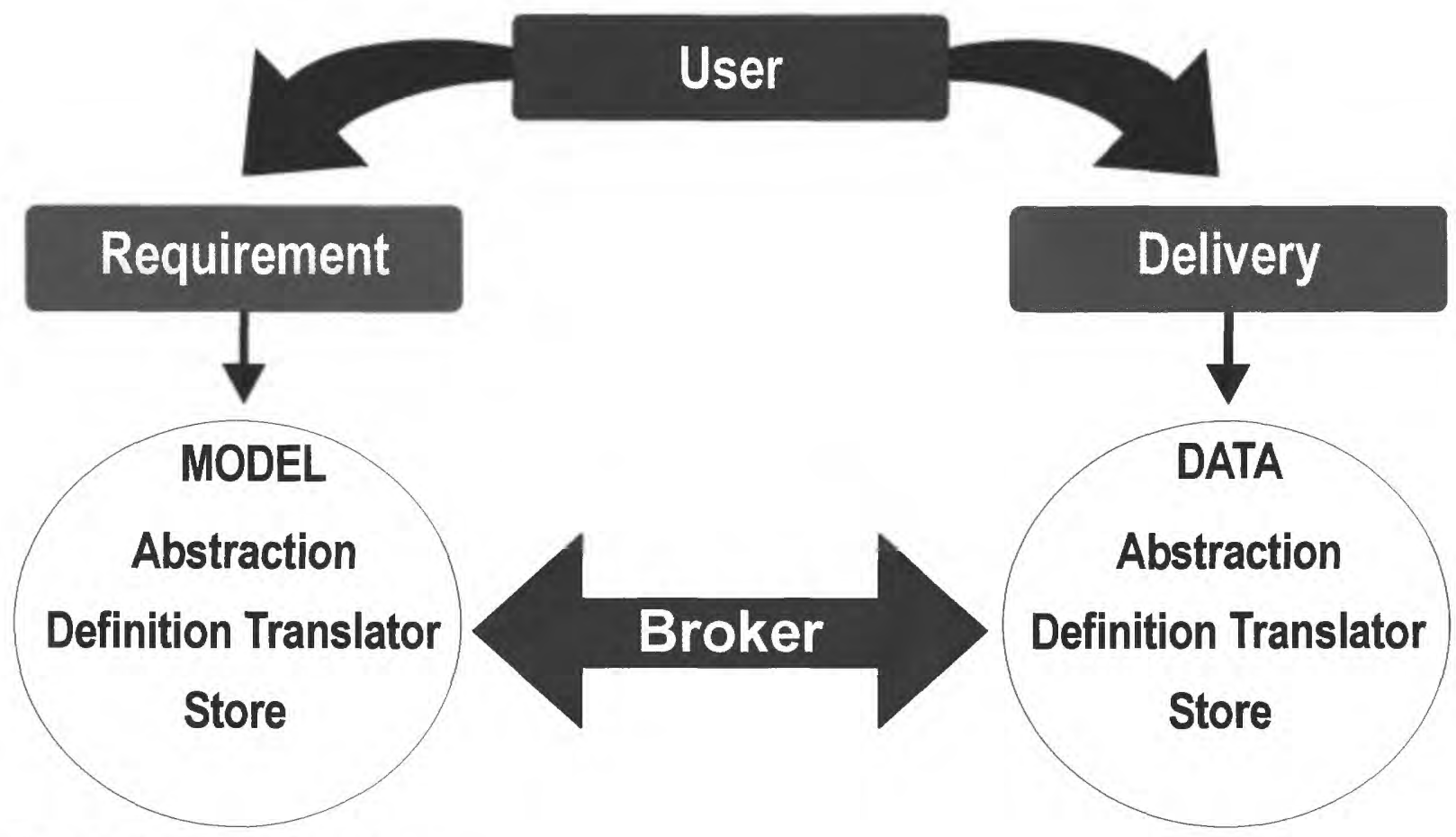

Figure 8. Broker services architecture.

\section{Definition Translator}

It is assumed that it is not possible (or even desirable) to define or enforce a universal standard on model/data/ computation specification or implementation. Thus to map the abstract definition to the actual elements, a definition translator is required. In a shopper/catalogue/ warehouse analogy, the definition translator may take the product identification generated from the catalogue description and returns, for example, what resources might be required to ship it, such as size, weight, cost, special handling, etc.).

\section{Store}

The data or model store is characterized not as a monolithic data depository but rather a set of pointers to the actual resources. In a warehouse analogy, the store takes a particular product identifier and tells the warehouse operator where that product is located.

\section{Strategies for implementation}

A multi-tiered strategy for advancing progress in this area is suggested. An overriding objective is to ensure that the decision support community is engaged in the process of defining and developing this functionality. The strategy is a market or user-focused approach to bridging the gaps between existing technologies.

\section{Tier 1}

- Literature review on model definition language Data definition languages through metadata specifications and interoperability activities are advancing rapidly. A similar effort for models needs to be launched.

- Test against marketplace Arguably, one of the barriers to decision support technology is the perceived lack of market potential by private sector technology providers.

- Government influence on technology trajectory The creation of broker services can be disabled by unwillingness to participate, even if the functions perform to specification. As these efforts develop, the government can assist by including requirements in contracts and bids supporting participation.

- Enable access to data In support of capturing "low hanging fruit," demonstration functions supporting brokered access to distributed data should be supported. 
This can occur through existing demonstration projects undertaken by the federal agencies and need not necessarily require new programs.

\section{Tier 2}

- De-couple models

- Formalize Definition Models

- Basic Broker Functionality (search/discovery)

- Maintain connection with CS community re GRID development

\section{Tier 3}

- Advanced Broker Function

- Implement within emerging computational GRID environment (second generation Web)

\section{Recommendations}

1. Workshop aimed at defining model components - Model Description Language

- Based on fundamental cleavages between types

- Look at ERDC Model catalog

2. Form multilateral evaluation group (e.g., OGC)

3. Make case for market

4. Need a synoptic program/for teaching and research

5. Consortia/partnership of compute service providers/ISP/and ASP

\section{Roles}

Government specs and requirements

Consortia - standards

Industry - widgets

\section{DSS Participants List}

\begin{tabular}{ll}
\hline Name & e-mail \\
\hline Brenda Faber & Bfaber@foresite-net.com \\
Peter Kenney & Peterk@usa.net \\
Fred Limp & Fred@cast.uark.edu \\
Paul Densham & Pdensham@geog.ucl.ac.uk \\
Wayne Schmidt & w-schmidt@cecer.army.mil \\
Jeff Holland & Hollanj@wes.army.mil \\
Robert Wallace & Wallacr@wes.army.mil \\
Kurt Buehler & Kurt@opengis.org \\
Susan Crow & Scrow@esri.com \\
George Leavesley & George@usgs.gov \\
Jim Westervelt & Westerve@uiuc.edu \\
Pat Black & Pbb@crrel.usace.army.mil \\
Gordon Plishker & Rgs_gap@shsu.edu \\
Darrell Nolton & Darrell.g.nolton@wrc01.usace.army.mil \\
John Lambie & Jlambie@gte.net \\
Mike Case & m-case@cecer.army.mil \\
Bill Goran & W-goran@cecer.army.mil \\
Maury Nyquist & Maury_nyquist@usgs.gov \\
Tom Gunther & Thomas_gunther@os.doi.gov \\
Ken Snyder & Ken_snyder@nrel.gov \\
Steve Fine & Fine.steven@epa.gov \\
Gene Lessard & Lessard@erols.com \\
Kelly Dilks & k-dilks@cecer.army.mil \\
Janis Buchanan & Jbuchanan@mail.arc.nasa.gov \\
Paul Turczynski & Pturczynski@autometrix.com \\
Doug Johnston & Johnston@gis.uiuc.edu \\
David Kirtland & Dakirtland@usgs.gov \\
Allison Newcomb & Newcome@wes.army.mil \\
& \\
\hline
\end{tabular}


Public reporting burden for this collection is estimated to average 1 hour per response, including time fo reviewing instructions, searching existing data sources, gathering and maintaining the data needed, and compieting and reviewing the collection of information. Send comments regarding this burden estmate or any oth aspect of this collection of information. including suggestions for reducing this burden, to Washington Headquarters Services, Directorate for information Operations ad Reports, 1215 Jefferson Davis Highway, Suite 1204, Arlington, VA 22202-4302, and to the Office of Management and Budget, Paperwork Reduction Project (0 $704-0$ Washington, DC 20503

\begin{tabular}{l|c}
$\begin{array}{l}\text { 1. AGENCY USE ONLY (Leave } \\
\text { Blank) }\end{array}$ & 2. REPORT DATE \\
& June 2001
\end{tabular}

3. REPORT TYPE AND DATES COVERED

Information and Technology Report

4. TITLE AND SUBTITLE

5. FUNDING NUMBERS

A Framework for Ecological Decision Support Systems: Building the Right Systems and Building the Systems Right

\section{AUTHOR(S)}

D'Erchia, F., C. Korschgen, M. Nyquist, R. Root, R. Sojda, and P. Stine

7. PERFORMING ORGANIZATION NAME(S) AND ADDRESSES

U.S. Department of the Interior

U.S. Geological Survey

Biological Resources Division

PERFORMING ORGANIZATION REPORT NUMBER

USGS/BRD/ITR--2001-

0002

\section{SPONSORING/MONITORING AGENCY NAME(S) AND ADDRESSES}

10. SPONSORING MONITORING

U.S. Department of the Interior

U.S. Geological Survey

11. SUPPLEMENTARY NOTES

12a. DISTRIBUTION/AVAILABILITY STATEMENT

Copies of this publication are available from the National Technical Information

Service, 5285 Port Royal Road, Springfield, Virginia 22161 (1-800-553-6847 or 703-

487-4650). Copies also are available to registered users from the Defense Technical

Information Center, Attn.: Help Desk, 8725 Kingman Road, Suite 0944, Fort Belvoir, Virginia 22060-6218 (1-800-225-3842 or 703-767-9050).

13. ABSTRACT (Maximum 200 words)

Workshops in the late 1990's launched the commitment of the U.S. Geological Survey's Biological Resources Division (BRD) to develop and implement decision support systems (DSS) applications. One of the primary goals of this framework document is to provide sufficient background and information for Department of the Interior (DOI) bureau stakeholders and other clients to determine the potential for DSS development. Such an understanding can assist them in carrying out effective land planning and management practices. This document provides a definition of DSS and its characteristics and capabilities. It proceeds to describe issues related to meeting resource managers needs, such as the needs for specific applications, customer requirements, information and technology transfer, user support, and institutionalization. Using the decision process as a means to guide DSS development and determine users needs is also discussed. We conclude with information on methods to evaluate DSS development efforts and recommended procedures for verification and validation.

\section{SUBJECT TERMB (Keywords)}

Adaptive management, Biological Resources Division, decision making process, decision support systems, DSS, resource managers, USGS
15. NUMBER OF PAGES

$50 \mathrm{p}$.

16. PRICE CODE
17. SECURITY CLASSIFICATION OF REPORT

Unlimited
18. SECURITY CLASSIFICATION OF THIS PAGE

Unlimited
19. SECURITY CLASSIFICATION OF 20. LIMITATION OF ABSTRACT ABSTRACT

Unlimited

Unlimited 



\title{
Technical Report Series
}

The Biological Resources Division publishes scientific and technical articles and reports resulting from the research performed by our scientists and partners. These articles appear in professional journals around the world. Reports are published in two report series: Biological Science Reports and Information and Technology Reports.

\section{Series Descriptions}

This series records the significant findings resulting from sponsored and cosponsored research programs. They may include extensive data or theoretical analyses. Papers in this series are held to the same peer-review and high quality standards as their journal counterparts.
These reports are intended for publication of book-length monographs; synthesis documents; compilations of conference and workshop papers; important planning and reference materials such as strategic plans, standard operating procedures, protocols, handbooks, and manuals; and data compilations such as tables and bibliographies. Papers in this series are held to the same peer-review and high quality standards as their journal counterparts.

\section{USGS-National Wetlands Research Center Technology \& Informatics Branch}

\author{
Chief \\ Gaye S. Farris
}

Production Staff

Editors Tammy M. Charron, (Johnson Controls World Services)

Rhonda F. Davis

Beth A. Vairin

Layout/Cover design Natalie G. Trahan, (Johnson Controls World Services)

Printing Liaison Susan M. Lauritzen 


\section{U.S. Department of the Interior U.S. Geological Survey}

As the Nation's principal conservation agency, the Department of the Interior has responsibility for most of our nationally owned public lands and natural resources. This responsibility includes fostering the sound use of our lands and water resources; protecting our fish, wildlife, and biological diversity; preserving the environmental and cultural values of our national parks and historical places; and providing for the enjoyment of life through outdoor recreation. The Department assesses our energy and mineral resources and works to ensure that their development is in the best interests of all our people by encouraging stewardship and citizen participation in their care. The Department also has a major responsibility for American Indian reservation communities.

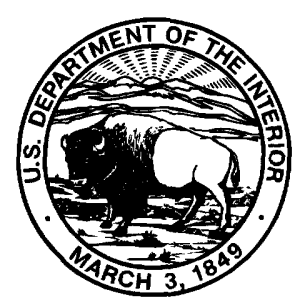

